\title{
Chinese herbal component, Praeruptorin E, enhances anti-asthma efficacy and prevents toxicity of aminophylline by targeting the NF-кB/PXR/CYP3A4 pathway
}

\author{
Ronghua $\mathrm{Xu}^{1,2 \#} \wedge$, Huiming Deng ${ }^{1,2 \#} \wedge$, Lianfang Gan ${ }^{1 \#}$, Lifan Zhong ${ }^{1}$, Yanxi Deng ${ }^{1}$, Qianru Wang ${ }^{1}$, \\ Chuanzhu Lv ${ }^{3,4}$, Ling Huang ${ }^{1,4,5}$ ^
}

${ }^{1}$ Hainan Province Key Laboratory for Drug Preclinical Study of Pharmacology and Toxicology Research, Hainan Medical University, Haikou, China; ${ }^{2}$ Department of Gastrointestinal Surgery, Huazhong University of Science and Technology Union Shenzhen Hospital, Shenzhen, China; ${ }^{3}$ Key Laboratory of Emergency and Trauma of Ministry of Education, Hainan Medical University, Haikou, China; ${ }^{4}$ Research Unit of Island Emergency Medicine, Chinese Academy of Medical Sciences, Hainan Medical University, Haikou, China; ${ }^{5}$ School of Hainan Provincial Drug Safety Evaluation Research Center, Hainan Medical University, Haikou, China

Contributions: (I) Conception and design: L Huang, R Xu, H Deng; (II) Administrative support: L Huang, R Xu; (III) Provision of study materials or patients: R Xu, H Deng; (IV) Collection and assembly of data: H Deng, L Gan, L Zhong, Y Deng, Q Wang; (V) Data analysis and interpretation: H Deng, L Gan; (VI) Manuscript writing: All authors; (VII) Final approval of manuscript: All authors.

\#These authors contributed equally to this work.

Correspondence to: Ling Huang. Hainan Province Key Laboratory for Drug Preclinical Study of Pharmacology and Toxicology Research, Hainan Medical University, No. 3 Xueyuan Road, Haikou 571199, China; Research Unit of Island Emergency Medicine, Chinese Academy of Medical Sciences, Hainan Medical University, No. 3 Xueyuan Road, Haikou 571199, China; School of Hainan Provincial Drug Safety Evaluation Research Center, Hainan Medical University, No. 3 Xueyuan Road, Haikou 571199, China. Email: puer6@163.com; Chuanzhu Lv. Key Laboratory of Emergency and Trauma of Ministry of Education, Hainan Medical University, No. 3 Xueyuan Road, Haikou 571199, China; Research Unit of Island Emergency Medicine, Chinese Academy of Medical Sciences, Hainan Medical University, No. 3 Xueyuan Road, Haikou 571199, China. Email: lvchuanzhu677@126.com.

Background: Aminophylline is widely used for the treatment of asthma, but the therapeutic dose is very close to the toxic dose, which makes this drug prone to accumulation poisoning. In the present study, we explored whether the Chinese herbal component, Praeruptorin E (PE), enhances anti-asthma efficacy and prevents the toxicity of aminophylline.

Methods: First, an ovalbumin (OVA)-induced mouse model of asthma, immunohistochemistry, pathological staining, and bronchoalveolar lavage fluid (BALF) were used to detect the lung condition of asthmatic mice. The content of Th2 cytokines in serum was measured by enzyme-linked immunosorbent assay (ELISA), and the expression of related proteins was detected by Western blotting and immunofluorescence. Concentrations of theophylline and its metabolites in rat serum were analyzed by liquid chromatographytandem mass spectrometry (LC-MS/MS). siRNA transfection and chromatin immunoprecipitation (ChIP) were used to investigate the mechanism of PE.

Results: PE was found to synergize with aminophylline to reduce the infiltration of inflammatory cells, collagen deposition, and mucus hyperplasia in the lungs of asthmatic mice. It inhibited the expression of Th2 cytokines, interleukin (IL)-4, IL-5, and IL-13; promoted lung tissue repair; and reduced the toxic effect of aminophylline on the heart. Moreover, LC-MS/MS analysis showed that PE reduced the plasma concentration of the parent theophylline and its metabolite 1,3-dimethyluric acid (1,3-DMU). PE facilitated aminophylline's suppression of nuclear factor- $\kappa \mathrm{B}(N F-\kappa B)$, and increased the expression of the xenobiotic nuclear receptor pregnane $\mathrm{X}$ receptor $(P X R)$ and its primary target gene, CYP3A11 [this is the mouse

^ ORCID: Ronghua Xu, 0000-0002-5745-8915; Huiming Deng, 0000-0002-1409-6926; Ling Huang, 0000-0002-5173-689X. 
homolog of cytochrome $\mathrm{P} 4503 \mathrm{~A}(C Y \mathrm{P} 3 A)]$ in the asthmatic mouse liver and in the L-02 human fetal hepatocyte cell culture model. In addition, the ChIP assay revealed that PE attenuated the binding of $N F-\kappa B$ to the promoter region of the PXR gene and prevented the suppression of $P X R$ gene expression by $N F-\kappa B$.

Conclusions: PE has a dual function in enhancing the immune regulation and anti-inflammatory effects of

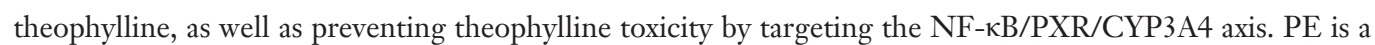
promising herbal medicine that will benefit asthmatics taking theophylline.

Keywords: Praeruptorin E (PE); aminophylline; nuclear factor- $\kappa \mathrm{B}(\mathrm{NF}-\kappa \mathrm{B})$; pregnane $\mathrm{X}$ receptor (PXR); asthma

Submitted Nov 30, 2021. Accepted for publication Feb 18, 2022.

doi: $10.21037 /$ atm-22-386

View this article at: https://dx.doi.org/10.21037/atm-22-386

\section{Introduction}

Asthma is a chronic inflammatory disease of the lungs, characterized by airway obstruction and high reactivity. There are about 300 million people with asthma worldwide, and about 250,000 asthma-related deaths occur every year $(1,2)$. Th2 cytokines [such as interleukin (IL)-4, IL-5, and IL-13] play a key role in the pathogenesis of allergic asthma. These cytokines promote eosinophil infiltration, the release of immunoglobulin $\mathrm{E}$ ( $\mathrm{IgE}$ ), airway hyperreactivity, and mucus secretion, leading to the development of allergic asthma (3-5). Currently, anti-airway allergic inflammatory drugs and bronchodilators are the main asthma therapies (6). Aminophylline has been used for the treatment of asthma for many years, producing smooth muscle relaxation and immune regulation, and having antiinflammatory activity (7). Although aminophylline has a good therapeutic effect on asthma symptoms, in a clinical study, it was found that $21 \%(9 / 43)$ of patients died from aminophylline poisoning, of which 4 patients had toxic levels of theophylline in their serum (8). Another study reported that treatment with aminophylline can lead to cardiac toxicity, such as arrhythmias, chest tightness, and elevated myocardial enzymes (9). One report demonstrated that monitoring plasma concentration levels of theophylline during administration could improve safety (10). However, the concentration of theophylline in the blood cannot be monitored continuously due to the limitations of clinical measurements. Therefore, there is an urgent need to find compatible drugs that can reduce the toxicity of aminophylline and enhance its efficacy in clinical practice.

Nuclear factor- $\kappa \mathrm{B}(\mathrm{NF}-\kappa \mathrm{B})$ is a multipotent transcription factor that has been shown to induce asthma both in mouse models and asthmatic patients (11). Inflammatory factors, such as IL-1 $\beta$, IL-4, and IL-5, which are regulated by $\mathrm{NF}-\kappa \mathrm{B}$, can promote the development of asthma, whereas cytokines regulated by $\mathrm{NF}-\kappa \mathrm{B}$ can promote the expression of NF- $\kappa B$ in asthma $(12,13)$. NF- $\kappa B$ activation is also closely associated with airway tissue remodeling (fibrosis of surrounding airway tissues, hyperplasia and hypertrophy of smooth muscle cells, and myxogenesis) (14). When asthmatics have airway inflammation and hyperresponsiveness, NF- $\mathrm{KB}$ and its inflammatory factors can reduce the metabolic clearance activity of theophylline and increase the incidence of theophylline accumulation toxicity, which is more likely to occur in children and elderly patients $(15,16)$. NF- $\kappa B$, a key factor in the inflammatory process, regulates the gene expression of cytochrome $\mathrm{P} 450$ $3 \mathrm{~A}(\mathrm{CYP} 3 \mathrm{~A})$ through the pregnane $\mathrm{X}$ receptor (PXR), thereby affecting drug metabolism (17). PXR activation can upregulate the expression of the metabolic enzyme CYP3A, promote drug metabolism, and inhibit the activity of NF- $\kappa B$ and the expression of NF- $\kappa B$ target genes $(18,19)$. Therefore, inhibition of the NF- $\kappa \mathrm{B}$ pathway is not only a synergistic anti-asthma effect, but also an effective strategy to reduce the risk of aminophylline poisoning.

Peucedanum praeruptorum Dunn is a perennial herb of the Peucedanum genus in the Apiaceae family. It has a variety of active ingredients that have antihypertensive, antiosteoporosis, and antitumor biological effects (20-22). It can also inhibit NF- $\kappa \mathrm{B}$ activity to produce antiinflammatory, anti-asthmatic, and antitussive phlegm effects (23). Our previous results indicated that the active components of Peucedanum praeruptorum Dunn could upregulate the expression and functional activity of CYP3A4 through the PXR pathway (24-26). In the present study, an ovalbumin (OVA)-induced asthma model in mice and in vitro experiments showed that Praeruptorin E (PE) could inhibit the expression of NF- $\kappa \mathrm{B}$ to enhance the 
effect of aminophylline treatment in asthma. In addition, the inhibition of $\mathrm{NF}-\kappa \mathrm{B}$ by $\mathrm{PE}$ promoted the expression of PXR and enhanced the functional activity of the enzyme CYP3A11 and reduced the accumulation of theophylline and 1,3-dimethyluric acid (1,3-DMU) in asthmatic mice. These findings indicate that $\mathrm{PE}$ has a dual function in enhancing the immune regulation and anti-inflammatory effects of theophylline, as well as preventing theophylline toxicity by targeting the $\mathrm{NF}-\kappa \mathrm{B} / \mathrm{PXR} / \mathrm{CYP} 3 \mathrm{~A} 4$ axis. Our findings are expected to reduce the incidence of adverse reactions to aminophylline in clinical treatment of asthma.

We present the following article in accordance with the ARRIVE reporting checklist (available at https://atm. amegroups.com/article/view/10.21037/atm-22-386/rc).

\section{Methods}

\section{Animals}

All experiments were approved by the Institutional Animal Care and Treatment Committee of Hainan Medical University (Ratified on October 16, 2017). All procedures involving animals were performed in accordance with the Guidelines for the Humane Treatment of Laboratory Animals (Ministry of Science and Technology of the People's Republic of China; policy No. 2006398). BALB/c male mice (weighing 18-22 g, drug efficacy study) and male Sprague-Dawley (SD) male rats (weighing 160-180 g, metabolic analysis) were purchased from Shanghai SLAC Laboratory Animal Co., Ltd. (Shanghai, China). All animals were breed under the specific pathogen-free in the Hainan Provincial Drug Safety Evaluation Research Center \{animal license No. SYXK [Qiong] 2016-0013\}. The mice were given standard rodent chow and secondary purified water. The feed environment was a 12-h light/dark cycle, temperature $22-25^{\circ} \mathrm{C}$, and humidity $40-70 \%$. The animals were adapted to the experimental environment for 7 days.

\section{Grouping and the asthma model}

The experimental design and dosage of PE (24) are shown in Figure $1 A, 1 B$. Briefly, for the asthma model, BALB/c mice and SD rats were intraperitoneally sensitized with $10 \mu \mathrm{g}$ or $10 \mathrm{mg}$ of OVA (Sigma-Aldrich) and 20 or $100 \mathrm{mg}$ $\mathrm{Al}(\mathrm{OH})_{3}$ gel on days 8 and 15 . From days 15 to 25 , the rats were challenged on 10 consecutive days with the administration of $1 \mathrm{mg} / \mathrm{mL}$ or $2 \%$ OVA inhalation, $30 \mathrm{~min} / \mathrm{day}$. The normal control group received the same volume of saline subcutaneously (days 8 and 15) and inhalation (days 15-25).

\section{Chemicals and reagents}

PE (purity $\geq 98.0 \%$ ) was purchased from Chengdu purechem-standard (Chengdu, China), the PE structure is shown in Figure $2 \mathrm{~A}$; aminophylline was obtained from Sigma-Aldrich (Louis, MO, USA); human liver L-02 cells were obtained from the Shanghai Cell Bank of the Chinese Academy of Sciences; RPMI-1640 medium and fetal bovine serum (FBS) were purchased from Gibco (Carlsbad, CA, USA); polyvinylidene difluoride (PVDF) membrane was obtained from Millipore (Billerica, CA, USA). The enhanced chemiluminescence (ECL) detection system was from Beyotime Biotechnology (Shanghai, China).

\section{Analysis of bronchoalveolar lavage fluid (BALF)}

After anesthetizing the BALB/c mice with chloral hydrate (Sigma-Aldrich), injected intraperitoneally, the mice were humanely killed, the left lungs were lavaged 3 times with cold phosphate-buffered saline (PBS), and BALF was harvested, A total of $1 \mathrm{~mL}$ of fresh BALF was taken and centrifuged at $1,500 \times \mathrm{g}$ for $10 \mathrm{~min}$ at $4{ }^{\circ} \mathrm{C} ; 10 \mu \mathrm{L}$ of BALF pellets were dropped on a glass slide to prepare a smear and then fixed in methanol for $30 \mathrm{~s}$. The BALF smear was immersed in Giemsa (Sigma-Aldrich) staining solution for $20 \mathrm{~s}$ at room temperature, and washed with PBS for $1 \mathrm{~min}$. Sections were then immersed in $1 \%$ acetic acid solution for $30 \mathrm{~s}$ after rinsing 3 times with PBS. Immune cells were then counted under a light microscope at $\times 400$ magnification.

\section{Enzyme-linked immunosorbent assay (ELISA)}

BALF and serum were collected from the left lung or retroorbital plexus. Concentrations of IL-4, IL-5, IL-13, IgE, NF- $\kappa$ B p65, lactate dehydrogenase (LDH), hydroxybutyrate dehydrogenase (HBD), creatine kinase (CK)-MB, CK, and aspartate aminotransferase (AST) were measured using ELISA kits (R\&D Systems, Minneapolis, MN, USA), according to the manufacturer's instructions.

\section{Electrocardiogram (ECG) collection}

After anesthesia, the limbs of mice were connected to the electrodes of the Powerlab multichannel physiological 
A

PE enhanced aminophylline anti-asthma experimental scheme

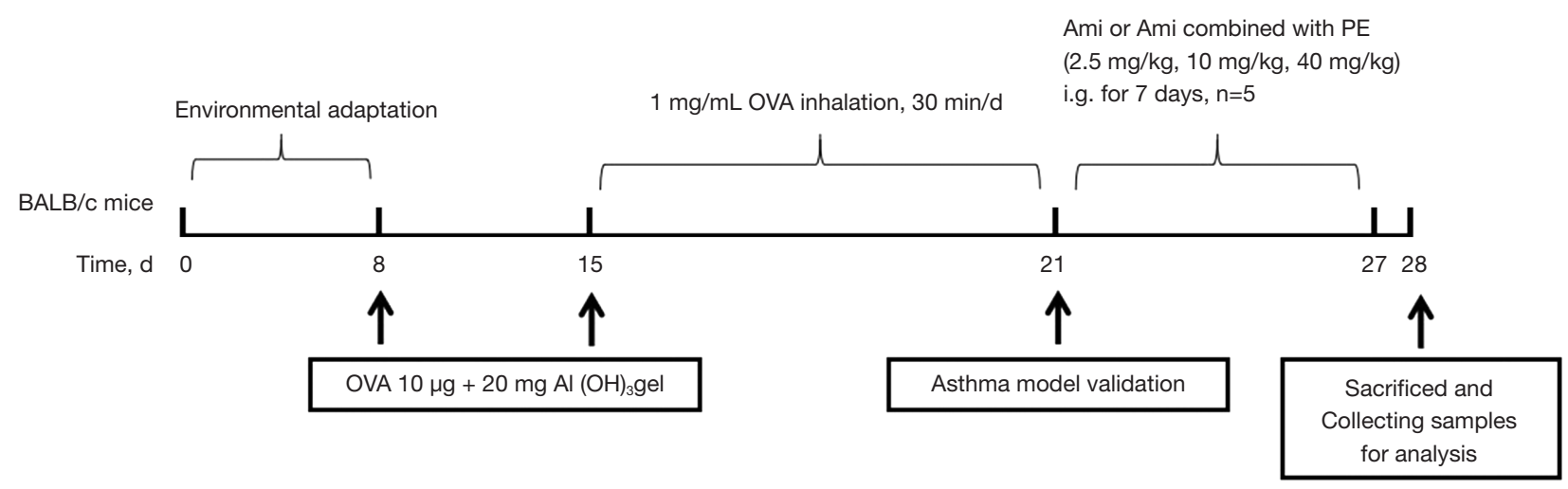

B

$P E$ reduced theophylline and its metabolites experimental scheme

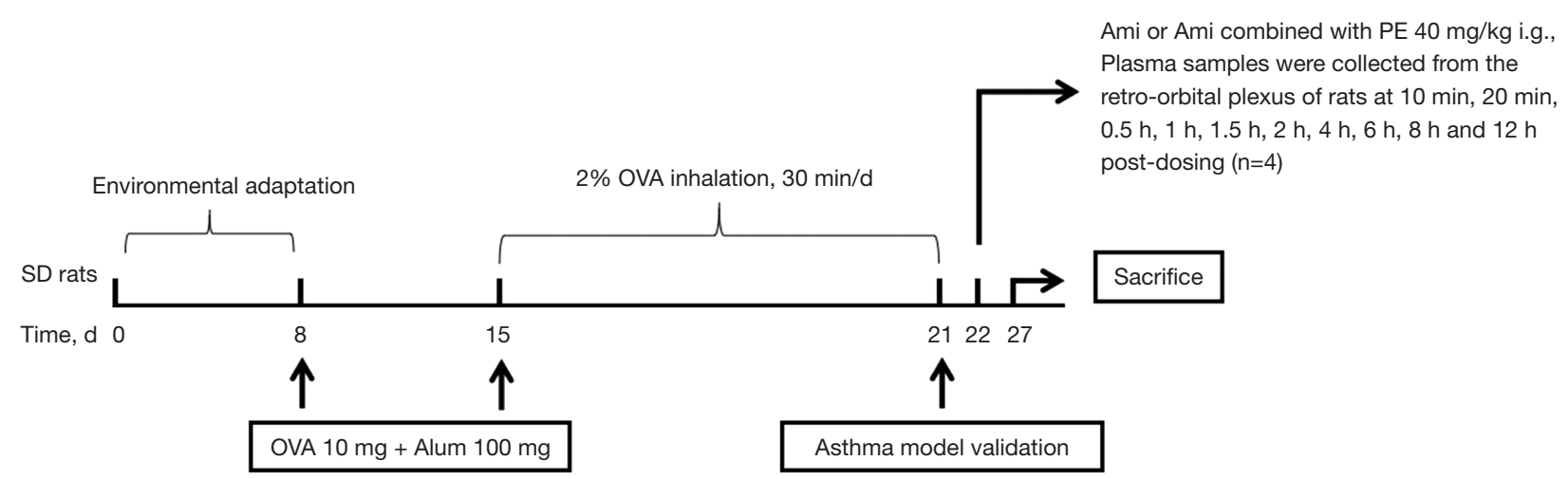

Figure 1 Schematic diagram of the experimental design. PE, Praeruptorin E; OVA, ovalbumin.

recorder (9020P; Nihon Kohden, Tokyo, Japan). Recording was started after display of a satisfactory lead II ECG. A continuously recorded 300-s ECG segment was printed to determine mouse heart rate and to analyze the ECG signal.

\section{Histopathological analysis}

Briefly, the right upper lobe lung and trachea were fixed in $4 \%$ formaldehyde for 4 days. Each tissue was sliced into 4- $\mu \mathrm{m}$ sections and stained with hematoxylin and eosin (H\&E). Periodic acid-Schiff (PAS) and Masson's trichrome (M-T) (Sigma-Aldrich) stains were used to detect the infiltration of inflammatory cells, acidic mucus chromophores, and collagen deposition based on the manufacturer's protocols. Lung and peri-bronchiole inflammation was evaluated using a score of $0-4$ (0, no cells; 1 , a few cells; 2 , a ring of cells 1 cell deep; 3 , a ring of cells 2-4 cells deep; 4, a ring of cells $>4$ cells deep). ImagePro Plus software (Media Cybernetics, Maryland, USA) was used to analyze of PAS and M-T stained specimens, as previously described (27).

\section{Immunohistochemical analysis}

The right lower lobe lung was fixed in $4 \%$ formaldehyde for 4 days. Each tissue was sliced into $4-\mu \mathrm{m}$ sections, dewaxed, and peroxidase inhibited. Specimens were incubated with the primary antibody at $4{ }^{\circ} \mathrm{C}$ overnight. Subsequently, they were washed with PBS 3 times and incubated with appropriate secondary antibodies (PowerVision Two- 
Step Histostaining Reagent, PV6001; Beijing Zhong Shan-Golden Bridge Biological Technology, Beijing, China) for $15 \mathrm{~min}$ at $37{ }^{\circ} \mathrm{C}$. The samples were stained with 3,3N-Diaminobenzidine Tetrahydrochloride (DBA) Horseradish Peroxidase Color Development Kit (P0203; Beyotime Biotechnology) and counterstained with hematoxylin (Sigma-Aldrich). The progress of the reaction was observed with the aid of a microscope (IX73; Olympus, Tokyo, Japan).

\section{Liquid chromatography-tandem mass spectrometry (LC- $M S / M S)$}

The instruments used for LC-MS/MS were the Agilent 1290 ultra-high performance LC system and Agilent 6410B triple quadrupole mass spectrometer (Thermo Scientific, Waltham, MA, USA).

\section{Method of LC}

A Capcell Pak MGII-C18 (2 mm × 100 mm, 3 m) (Shiseido, Tokyo, Japan) was used as the chromatographic column. Mobile phase A used pure water and mobile phase B used methanol, both containing $0.5 \%$ acetic acid. The gradient elution procedure was as follows: $0 \mathrm{~min} \rightarrow$ mobile phase $\mathrm{B}$ $10 \%, 0.5 \mathrm{~min} \rightarrow$ mobile phase B $30 \%, 1.0 \mathrm{~min} \rightarrow$ mobile phase B 90\%, 2 min $\rightarrow$ mobile phase B 90\%, $2.3 \mathrm{~min} \rightarrow$ mobile phase B $93 \%, 2.5 \mathrm{~min} \rightarrow$ mobile phase B $10 \%$, and $0.5 \mathrm{~min} \rightarrow$ mobile phase B $30 \%$. Other conditions included column temperature of $25^{\circ} \mathrm{C}$; injection volume of $1 \mu \mathrm{L}$, flow rate of $0.3 \mathrm{~mL} / \mathrm{min}$ and running time of $4 \mathrm{~min}$. Under the above conditions, the baseline separation was realized between the targeting analyte and the internal standard.

\section{MS method}

The electrospray ion source positive ion detection and multireaction monitoring methods were used for mass spectrometry detection. The mass spectrum parameters were capillary voltage $+4,000 \mathrm{~V}$ with capillary temperature of $350{ }^{\circ} \mathrm{C}$. The drying gas flow rate was $10 \mathrm{~L} / \mathrm{min}$ and atomized gas at $30 \mathrm{psi}$. The specific detection method including ion pair $(\mathrm{m} / \mathrm{z})$, fragmentor, and collision energy (CE) for each analyte were as follows:

Theophylline: ion pair $179.2 \rightarrow 164.1 \mathrm{~m} / \mathrm{z}$, fragmentor 104 V, CE 16 V;

1,3-DMU: ion pair $195.1 \rightarrow 180.1 \mathrm{~m} / \mathrm{z}$, fragmentor $119 \mathrm{~V}$, CE $12 \mathrm{~V}$;

1 -Methyluric acid (1-MU): ion pair $181.0 \rightarrow 138.1 \mathrm{~m} / \mathrm{z}$, fragmentor $129 \mathrm{~V}, \mathrm{CE} 12 \mathrm{~V}$.

\section{Standard curve}

A total of $50 \mu \mathrm{L}$ blank rat plasma was mixed with a series of working solutions, including $5 \mu \mathrm{L}$ theophylline $(0.5,1,2,5$, 10, 20, 50, 100, 100, 200, 500, 1,000 $\mathrm{g} / \mathrm{mL}), 1-\mathrm{MU}, 1,3-$ DMU (0.05, 0.1, 0.2, 0.5, 1, 2, 5, 10, 20, 50, $100 \mu \mathrm{g} / \mathrm{mL})$, and $5 \mu \mathrm{L}$ internal standard solution $(1 \mu \mathrm{g} / \mathrm{mL}$ toluene sulfonylurea, aqueous solution). After adding $150 \mu \mathrm{L}$ acetonitrile and vortexing for $10 \mathrm{~min}$, the solution was centrifuged at $14,000 \times \mathrm{g}$ and $4{ }^{\circ} \mathrm{C}$ for $10 \mathrm{~min}$. Subsequently, $1 \mu \mathrm{L}$ supernatant was injected for the LC-MS/MS analysis.

\section{Quality control of sample}

A total of $50 \mu \mathrm{L}$ blank rat plasma was mixed with a series of working solutions, including $5 \mu \mathrm{L}$ theophylline (1, 100, $800 \mu \mathrm{g} / \mathrm{mL}), 1-\mathrm{MU}(0.1,10,80 \mu \mathrm{g} / \mathrm{mL}), 1,3-\mathrm{DMU}(1,10$, $80 \mu \mathrm{g} / \mathrm{mL})$, and $5 \mu \mathrm{L}$ internal standard solution $(1 \mu \mathrm{g} / \mathrm{mL}$ toluene sulfonylurea, aqueous solution). After adding 150 acetonitrile and vortexing for $10 \mathrm{~min}$, the solution was centrifuged at $14,000 \mathrm{~g}$ and $4^{\circ} \mathrm{C}$ for $10 \mathrm{~min}$. Subsequently, $1 \mu \mathrm{L}$ supernatant was injected for LC-MS/MS analysis.

\section{Experimental animal sample}

Fifty $\mu \mathrm{L}$ plasma was mixed with $5 \mu \mathrm{L}$ water and $5 \mu \mathrm{L}$ internal standard solution $(1 \mu \mathrm{g} / \mathrm{mL}$ toluene sulfonylurea, aqueous solution). After mixing, $150 \mu \mathrm{L}$ acetonitrile was added and vortexed for $10 \mathrm{~min}$, followed by centrifugation at $14,000 \times \mathrm{g}$ and $4{ }^{\circ} \mathrm{C}$ for $10 \mathrm{~min}$. Subsequently, $1 \mu \mathrm{L}$ supernatant was injected for the LC-MS/MS analysis.

\section{Cell culture and transfection}

L-02 cells were cultured in RPMI-1640 containing supplements of FBS (10\%), penicillin $(100 \mathrm{U} / \mathrm{mL})$, and streptomycin $(100 \mu \mathrm{g} / \mathrm{mL})$ (Gibco) in a humidified sterile incubator at $37{ }^{\circ} \mathrm{C}$, with gaseous $5 \% \mathrm{CO}_{2}$ added to the atmosphere.

siRNA-PXR was designed and synthesized by Gene Pharma (Shanghai, China). The transfection of siRNAPXR was carried out using Lipofectamine 2000 transfection reagent (Gibco), according to the manufacturer's protocol. The L-02 cells were infected for $72 \mathrm{~h}$, then the stably transfected cells were treated with $\mathrm{PE}$ and lipopolysaccharide (LPS) (Sigma-Aldrich) for $24 \mathrm{~h}$.

\section{Reverse transcription polymerase chain reaction (RT-PCR)}

Total RNA was extracted from L-02 cell lung and liver tissue using TransZol Reagent (Generay, 1703G01, 
Shanghai, China). Reverse transcription was performed using HiScript-II Q RT SuperMix for qPCR (Vazyme, 7E092G6). Qualitative reverse transcription PCR (qRTPCR) was performed using ChamQ SYBR Color qPCR Master Mix (Vazyme, 7E092G6, Nanjing, China) and a CFX Connect Real-Time PCR System instrument (BioRad, Hercules, CA, USA), with the supporting analysis software, Bio-Rad CFX Manager (Bio-Rad, Hercules, CA, USA). The cycling conditions were as follows: $95^{\circ} \mathrm{C}$ for $30 \mathrm{~s}$, followed by 35 cycles at $95^{\circ} \mathrm{C}$ for $10 \mathrm{~s}, 60^{\circ} \mathrm{C}$ for $30 \mathrm{~s}, 60{ }^{\circ} \mathrm{C}$ for $30 \mathrm{~s}$ plate read. The sequences of the primer sets (Takara Bio, Talian, China) used for this analysis were as follows: $N F-\kappa B: 5$ '-AGGATTTCGATTCCGCTACG-3' (forward) and 5'-CTCACAGTGCTTGCCCACC-3' (reverse), PXR: 5'-ATGGACGCTCAGATGCAAAC-3' (forward) and 5'-GGAGGGAGGTTGGTAGTTCC-3' (reverse), CYP3A4: 5' -CAATAAGGCACCACCCACCTAT-3' (forward) and 5'-AGGTTTGCCTTTCTCTGCC-3' (reverse), CYP3A11: 5'-GGCAAGCCTGTTACTATGAA AG-3' (forward) and 5'-ACTGAGAAGAGCAAAGGATCA A-3' (reverse), CYP1A2: 5'-ATCCTGGAGATCTACCGA TACA-3' (forward) and 5'-TATGTAGATACAGCGCTCC TTG-3' (reverse), CYP2E1: 5'-CCAACTCTGGACTCCC TTTTAT-3' (forward) and 5'-ACGCCTTGAAATAGTCA CTGTA-3' (reverse), and actin: 5'-CCCATCTATGAGGG TTACGC-3' (forward) and 5'-TTCTTGCTGAATCT TTCAGGGAG-3' (reverse). The results were analyzed using a $2^{-\Delta \Delta \mathrm{Ct}}$ relative quantification method, and each sample was tested in triplicate with 5 wells per group.

\section{Western blotting}

Lung and liver tissues and L-02 cells were lysed in RIPA buffer, and a BCA kit (Beyotime Biotechnology) was used to quantify the level of protein in a sample. Protein bands were separated by polyacrylamide gels electrophoresis (SDS-PAGE, 8-14\%) and then repositioned on PVDF membranes. After appropriate blockade, PVDF membranes were incubated with the following primary antibodies: NF-кB p65 $(1: 1,000)$ (Cell Signaling Technology, Boston, MA, USA); PXR; CYP3A1, CYP1A2, and CYP2E1 $(1: 1,000)$ (Abcam, Cambridge, MA, USA); GAPDH $(1: 1,000)$ (MAB5465, MultiSciences, Hangzhou, China); and goat antirabbit IgG $(1: 5,000)$ (70-GAR007, MultiSciences), then incubated at room temperature with secondary antibodies for $1 \mathrm{~h}$. ECL chemicals (Beyotime Biotechnology) were used to examine the target proteins. An image analyzer system (ChemiDoc XRS+; Bio-Rad, Hercules, CA, USA) was used to quantify the results.

\section{Chromatin immunoprecipitation (ChIP)}

ChIP assays were conducted using a SimpleChIP Plus Enzymatic Chromatin IP Kit (Cell Signaling Technology), according to the manufacturer's instructions. Briefly, chromatin from cross-linked L-02 cells was sheared by sonication and incubated overnight with specific antibodies (NF-kB; Cell Signaling Technology) followed by proteinase $\mathrm{K}$ decrosslinking and purified DNA. Precipitated DNA and input DNA were analyzed using qualitative PCR (qPCR), and the results were presented as normalization to the input DNA. The results were analyzed and normalized by the $\mathrm{Ct}$ value obtained by qPCR, \% Input $=2^{-\Delta \mathrm{Ct}}$ (normalized ChIP) $\times 100 \%$. The primers for PXR were as follows: 5'-TACATAAAATACCTAGAATA-3' (forward) and 5'-ATTTAAATGGTTAATTTTAT-3' (reverse).

\section{Molecular docking}

We searched for the structural formula of PE (ID:013078) in TCMSP (https://www.tcmsp-e.com/). The structure

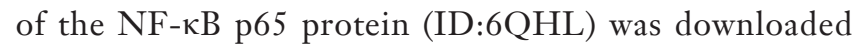
from the crystal structure data of PDB (https://www.pdbus. org/). AutoDock software (version 1.5.6, Scripps Research Institute, San Diego, CA, USA) was used to eliminate the water molecules of the target protein, and to add non-polar hydrogen and calculate the Gasteiger charge. The ligand structure was optimized in an MM2 force field by using Chem3D software (CambridgeSoft, MA, USA). AutoDock Vina 1.1.2 software was used for docking and Visual Studio software (2016, Microsoft, Redmond, USA) was used to visualize the docking results and select the conformation with the lowest interaction energy.

\section{Statistical analysis}

The experimental results are expressed as the mean \pm standard error of the mean, and the differences between groups were analyzed by one-way analysis of variance and Student's $t$-test using GraphPad Prism 8 (GraphPad Software, San Diego, CA, USA). $\mathrm{P}<0.05$ indicated that the difference was statistically significant. All in vitro data are representative of three independent experiments. 


\section{Results}

\section{PE enhances the inbibitory effect of aminophylline on OVA-induced inflammation}

Giemsa and H\&E staining was used to investigate whether PE could enhance the therapeutic effect of aminophylline on airway inflammation induced by OVA in mice. As shown in Figure 2B, the total number of inflammatory cells, eosinophils, monocytes, neutrophils, and lymphocytes in the OVA group was significantly higher than in the control group. In contrast, the total number of inflammatory cells and eosinophils in the aminophylline group was lower than in the OVA group, while the aminophylline + PE group exhibited even lower numbers than the aminophyllinealone group. The results revealed that PE could enhance aminophylline efficacy and reduce inflammatory effects in the trachea.

The H\&E staining results showed that the lung tissue structure was normal without any pathological changes in the control group. A large number of inflammatory cells was observed in the OVA group, mainly eosinophils and neutrophils. The alveolar walls were significantly thickened, most of the alveolar cavities were shrunken or even collapsed, and some of the alveoli were overextended. The aminophylline group exhibited some inflammatory cell infiltration, a small number of eosinophils, and local thickening of the alveolar walls. The number of inflammatory cells in the aminophylline $+\mathrm{PE}$ group was significantly lower than in the aminophylline group, and only a small number of eosinophils were found. The local alveolar wall was slightly thickened and some alveolar structures were normal, with a few alveolar dilatations. The least severe pathological changes were observed in the aminophylline $+40 \mathrm{mg} / \mathrm{kg}$ PE group. At the same time, the pulmonary pathological immune score of the aminophylline $+\mathrm{PE}$ group was lower than for the aminophylline group (Figure 2C,2D).

In the OVA group, the bronchial mucosa was loose and exhibited edema, epithelial cilia were adherent and prostrate, and the pseudo-lamellar structure had disappeared. The submucosal tissue was infiltrated with numerous inflammatory cells, including eosinophils, neutrophils, and monocytes. In the aminophylline group, the mucosal epithelium exhibited edema, part of the mucosal epithelium was exfoliated, while part of the mucosal epithelium was relatively normal with obvious cilium structures intact. Many inflammatory cells were observed in the submucosa, and part of the airway mucosa and submucosa was exfoliated. In the aminophylline + $\mathrm{PE}$ group, the degree of mucosal epithelial edema was lower than in the aminophylline group. The infiltration of submucosal inflammatory cells was lower than in the aminophylline group with minimal, if any, eosinophils present. In addition, the bronchial pathological immune score of the aminophylline + PE group was lower than that of the aminophylline group (Figure $2 E, 2 F$ ).

In addition to asthma mouse lung and bronchus inflammation manifestations, PAS and M-T stains were also used to observe mucus and collagen deposition in lung tissue (27). The results revealed that OVA group mouse lungs displayed remarkably increased airway acidic mucus secretion and collagen accumulation. Mucus secretion and collagen accumulation in asthmatic mice lung tissues was improved in the aminophylline group. In contrast, the mucus secretion and collagen deposition in the aminophylline + PE group was less than in the aminophylline treatment group (Figure $3 A-3 D$ ). These results indicated that $\mathrm{PE}$ can enhance the effect of aminophylline by reducing inflammation, mucus secretion, and collagen cell fibrosis in asthmatic mouse lungs.

\section{$P E$ promotes aminophylline to reduce OVA-induced serum $N F-\kappa B, \operatorname{IgE}$, and $T b 2$ cytokine concentrations}

Th2 cytokines, IgE, and NF- $\kappa \mathrm{B}$ play key roles in the pathogenesis of allergic asthma. Therefore, the concentrations of Th2 cytokines in BALF and serum concentrations of $\operatorname{IgE}$ and $\mathrm{NF}-\kappa \mathrm{B}$ p 65 were measured to investigate the synergism of $\mathrm{PE}$ with aminophylline in reducing airway inflammation. Figure $4 A-4 E$ shows that the concentrations of IL-4, IL-5, and IL-13 in BALF and serum $\operatorname{IgE}$ and NF- $\mathrm{NB}$ p65 in the OVA group were significantly higher than in the control group. Treatment with aminophylline significantly reduced IL-4, IL-5, and IL-13 in BALF and serum IgE and NF- $\mathrm{kB}$ p65 concentrations, while the addition of PE during aminophylline treatment markedly reduced these concentrations. To investigate further the expression of $\mathrm{NF}-\kappa \mathrm{B}$ p 65 in the lungs of asthmatic mice, we performed immunofluorescence analysis and found that the expression of NF- $\mathrm{\kappa B}$ p65 in asthmatic mice was significantly lower in the aminophylline $+\mathrm{PE}$ group than in the aminophylline alone group (Figure 4F,4G). To further demonstrate that $\mathrm{PE}$ had potential in binding

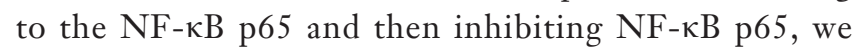
performed molecular docking. The binding modes of $\mathrm{PE}$ with the NF-кB p65 complex are illustrated in Figure 4H-47, 
A<smiles>C/C=C(/C)C(=O)O[C@H]1[C@H](OC(=O)CC(C)C)c2c(ccc3ccc(=O)oc23)OC1(C)C</smiles>

Cas: $78478-28-1 \quad \mathrm{C}_{24} \mathrm{H}_{28} \mathrm{O}_{7}$
B

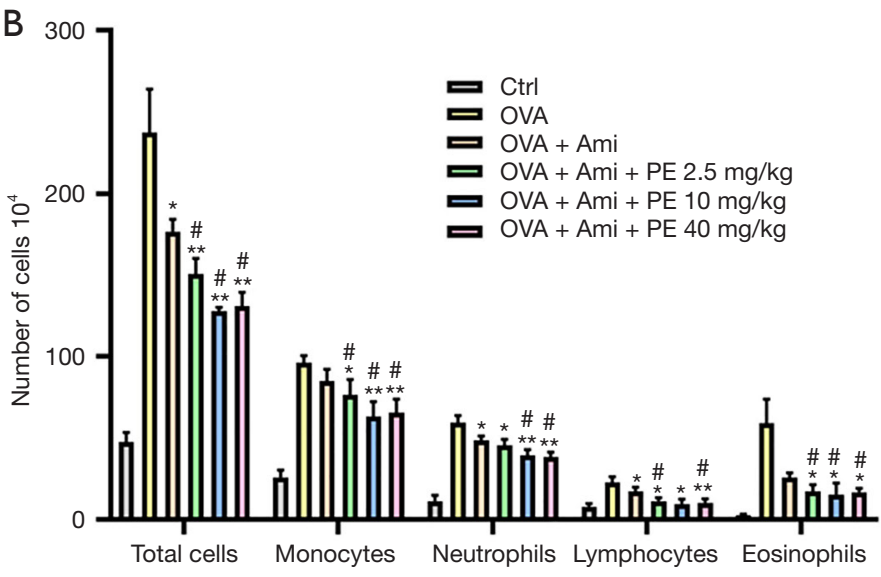

C
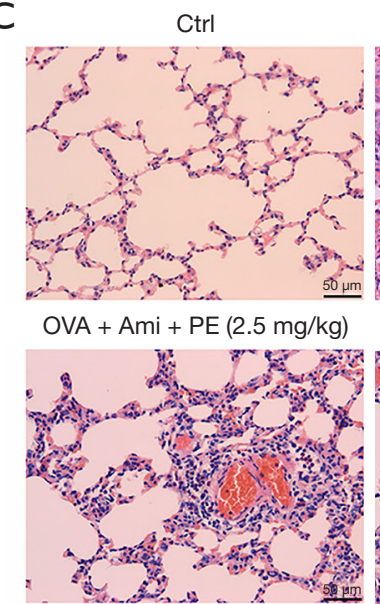

E

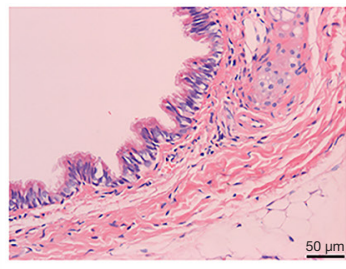

$\mathrm{OVA}+\mathrm{Ami}+\mathrm{PE}(2.5 \mathrm{mg} / \mathrm{kg})$

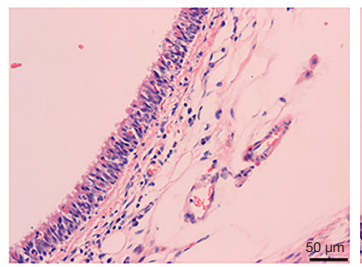

OVA
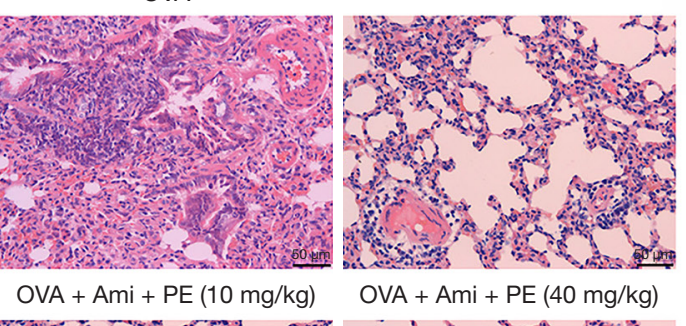

$\mathrm{OVA}+\mathrm{Ami}+\mathrm{PE}(40 \mathrm{mg} / \mathrm{kg})$

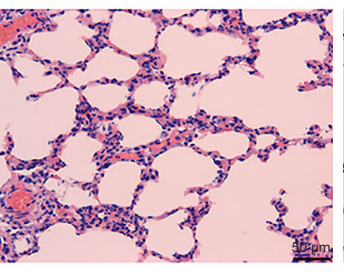

OVA

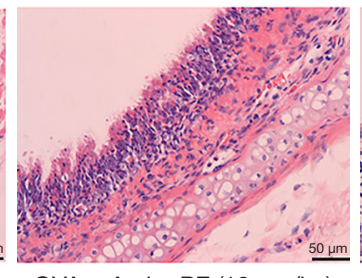

$O V A+A m i+P E(10 \mathrm{mg} / \mathrm{kg})$

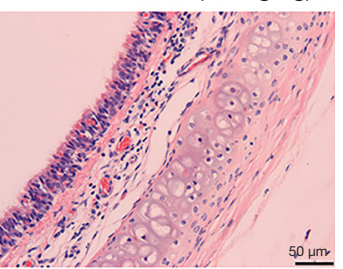

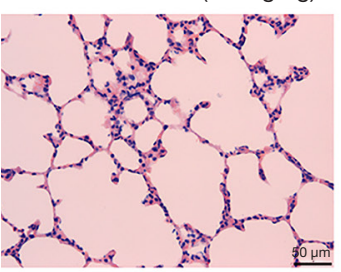

$\mathrm{OVA}+\mathrm{Ami}$
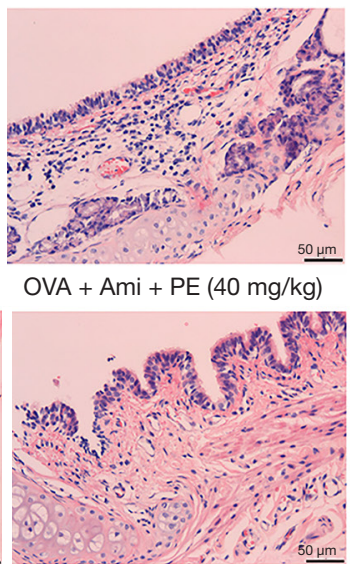

$O V A+A m i+P E(40$ mg/kg)
D

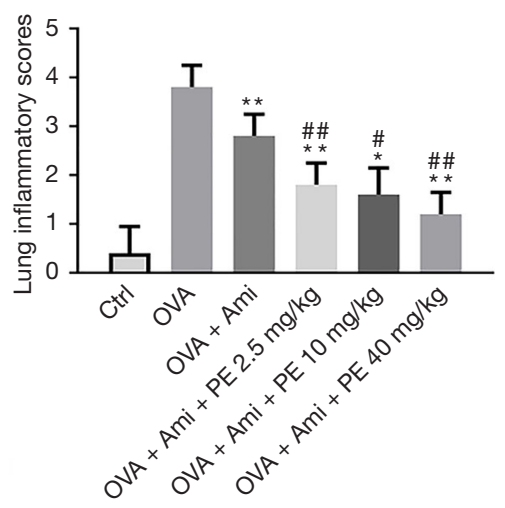

$\mathrm{F}$

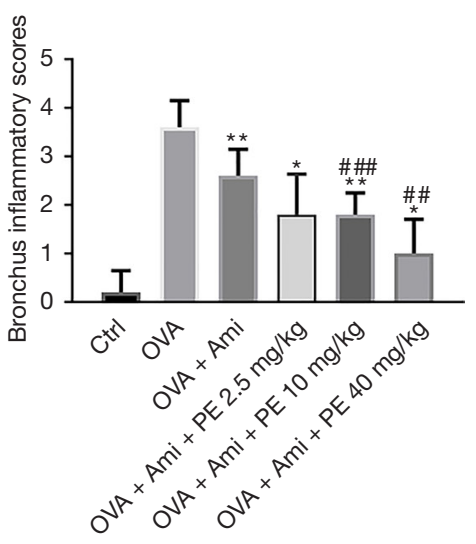

Figure 2 PE cooperates with Ami to reduce lung inflammation in asthmatic mice. (A) Chemical structure of PE. (B) Total number of inflammatory cells, monocytes, neutrophils, eosinophils, and lymphocytes in BALF. (C,D) H\&E staining and the pathological immune score of lung tissue in asthmatic mice. (E,F) H\&E staining and the pathological immune score of bronchi tissue in asthmatic mice. OVA + Ami group, OVA + Ami + PE $2.5 \mathrm{mg} / \mathrm{kg}$ group, OVA + Ami + PE $10 \mathrm{mg} / \mathrm{kg}$ group and OVA + Ami + PE $40 \mathrm{mg} / \mathrm{kg}$ group compared with the OVA group, ${ }^{*} \mathrm{P}<0.05,{ }^{*} \mathrm{P}<0.01$; OVA + Ami $+\mathrm{PE} 2.5 \mathrm{mg} / \mathrm{kg}$ group, OVA $+\mathrm{Ami}+\mathrm{PE} 10 \mathrm{mg} / \mathrm{kg}$ group and OVA $+\mathrm{Ami}+\mathrm{PE} 40 \mathrm{mg} / \mathrm{kg}$ group compared with the OVA + Ami group, ${ }^{\#} \mathrm{P}<0.05,{ }^{\# \#} \mathrm{P}<0.01,{ }^{\# \# \#} \mathrm{P}<0.001 . \mathrm{n}=5$. PE, Praeruptorin E; Ami, aminophylline; BALF, bronchoalveolar lavage fluid; H\&E, hematoxylin and eosin; ctrl, control; OVA, ovalbumin. 
A

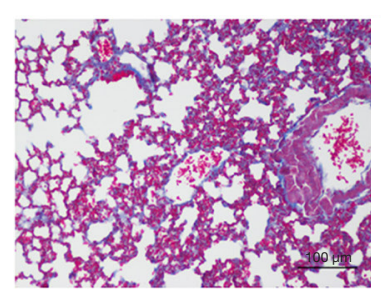

OVA + Ami + PE (2.5 mg/kg)

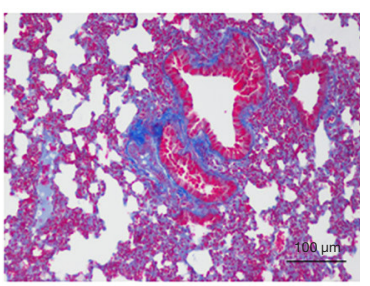

C

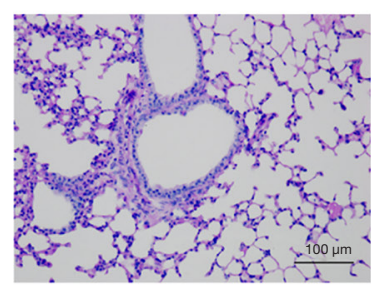

OVA + Ami + PE (2.5 mg/kg)

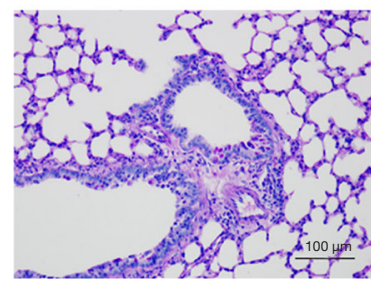

OVA

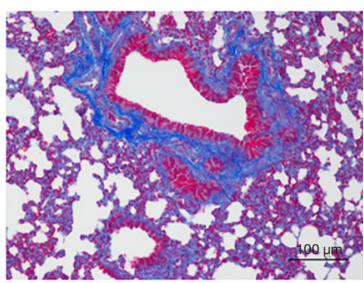

$O V A+A m i+P E(10 \mathrm{mg} / \mathrm{kg})$

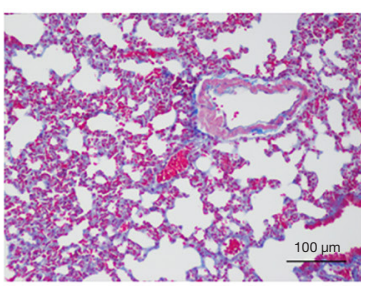

OVA

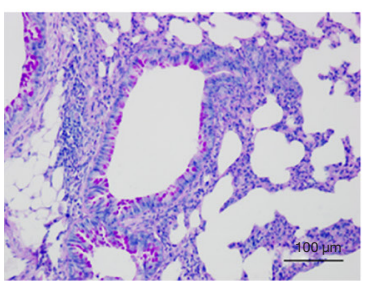

$O V A+A m i+P E(10 \mathrm{mg} / \mathrm{kg})$

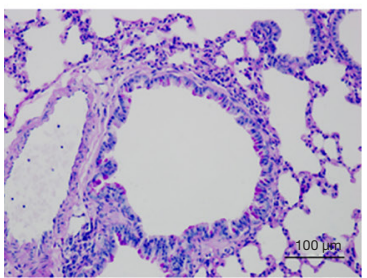

OVA + Ami

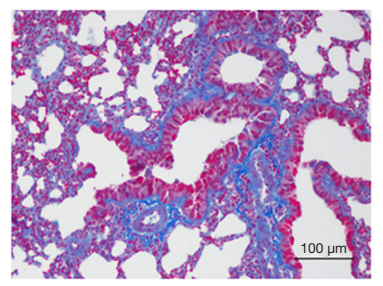

$O V A+A m i+P E(40 \mathrm{mg} / \mathrm{kg})$

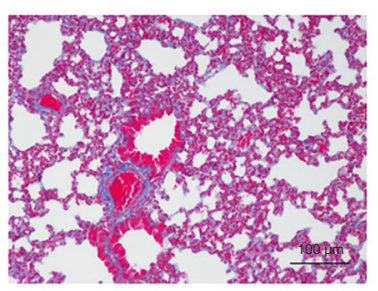

OVA + Ami

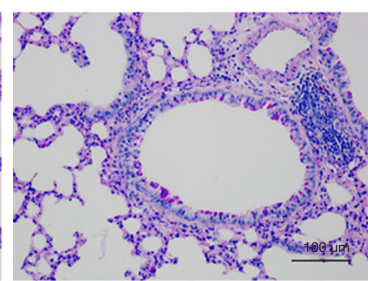

$\mathrm{OVA}+\mathrm{Ami}+\mathrm{PE}(40 \mathrm{mg} / \mathrm{kg})$

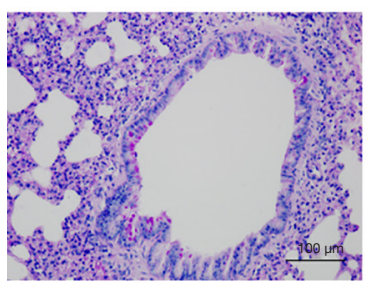

B

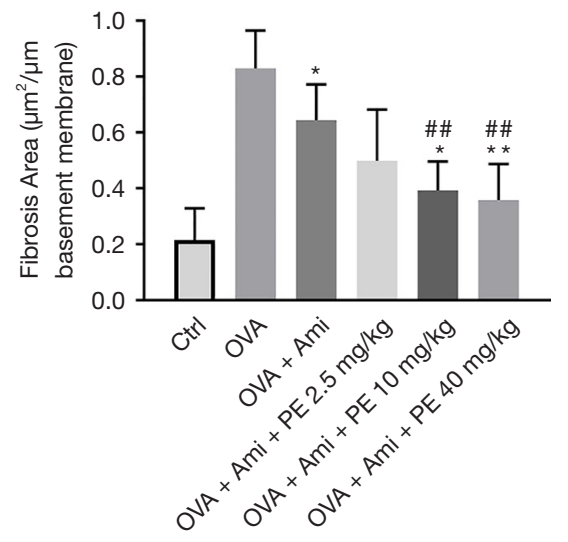

D

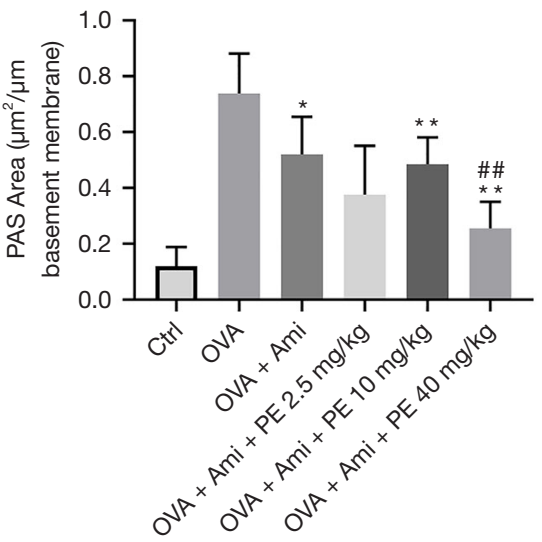

Figure $3 \mathrm{PE}$ enhanced the effect of Ami on the reduction of mucus secretion and collagen deposition in asthmatic mice lungs. (A,B) M-T staining and fibrosis area in the bronchial basement membrane determined by Image-Pro Plus software analysis. (C,D) PAS staining and PAS-positive areas in the bronchial basement membrane. OVA + Ami group, OVA + Ami + PE $2.5 \mathrm{mg} / \mathrm{kg}$ group, OVA + Ami + PE $10 \mathrm{mg} / \mathrm{kg}$ group and OVA + Ami + PE $40 \mathrm{mg} / \mathrm{kg}$ group compared with the OVA group, ${ }^{*} \mathrm{P}<0.05,{ }^{* *} \mathrm{P}<0.01 ; \mathrm{OVA}+\mathrm{Ami}+\mathrm{PE} 2.5 \mathrm{mg} / \mathrm{kg}$ group, OVA + $\mathrm{Ami}+\mathrm{PE} 10 \mathrm{mg} / \mathrm{kg}$ group and OVA + Ami + PE $40 \mathrm{mg} / \mathrm{kg}$ group compared with the OVA + Ami group, ${ }^{\# \#} \mathrm{P}<0.01$. n=5. PE, Praeruptorin E; Ami, aminophylline; M-T, Masson's trichrome; PAS, periodic acid-Schiff; ctrl, control; OVA, ovalbumin.

the free energy of binding was $-6.71 \mathrm{kcal} / \mathrm{mol}$. PE forms Van der Waals force with $\mathrm{Arg}^{131}, \mathrm{Gly}^{130}, \mathrm{Leu}^{222}, \mathrm{Asn}^{42}, \mathrm{Ser}^{133}$, $\mathrm{Phe}^{119}$, and a carbon-hydrogen bond with Gly ${ }^{171}$ and Lys ${ }^{122}$ of the $\mathrm{P}$ chain. Moreover, $\mathrm{PE}$ forms $\pi$-alkylation with $\mathrm{Pro}^{129}$, $\mathrm{Ile}^{219}, \mathrm{Pro}^{167}, \mathrm{Arg}^{132}, \mathrm{Ile}^{128}$ of the a-chain, and $\mathrm{Leu}^{218}, \mathrm{Ile}^{168}$ of the A-chain of NF- $\mathrm{KB}$ p65. These findings indicate that PE could enhance aminophylline efficacy to reduce the level of Th2 cytokines, IgE, and NF- $\mathrm{KB}$ p65 in asthmatic mice.

\section{PE ameliorates aminophylline cardiotoxicity and reduces the accumulation of aminophylline metabolites in vivo}

Cardiotoxicity is a common adverse reaction to aminophylline, manifested as arrhythmia and hypofunction of the heart $(9,28)$. Therefore, we investigated whether $\mathrm{PE}$ could reduce the cardiotoxicity of aminophylline at a concentration of $450 \mathrm{mg} / \mathrm{kg}$, which is 6 times the usual dose of aminophylline that induces cardiotoxicity. The 
A

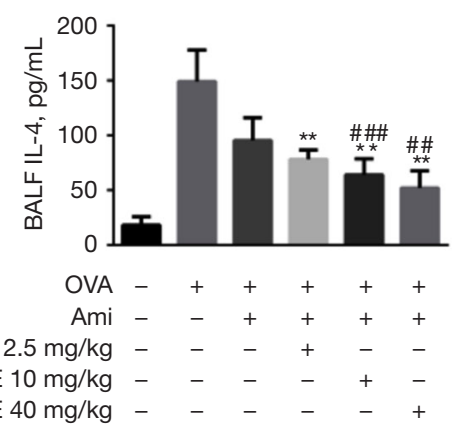

D

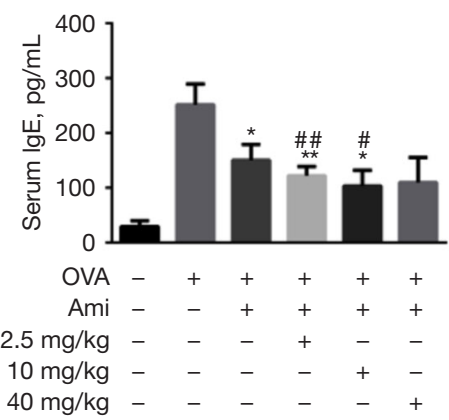

B

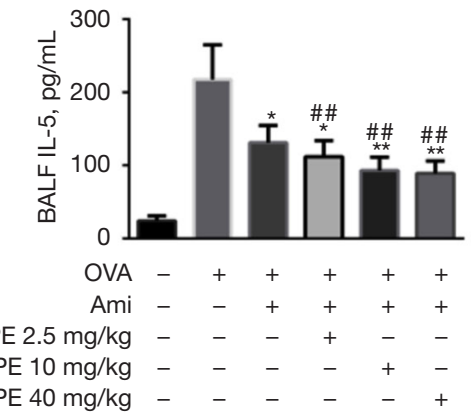

E

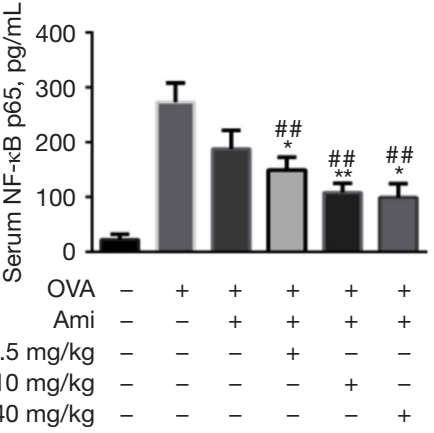

C

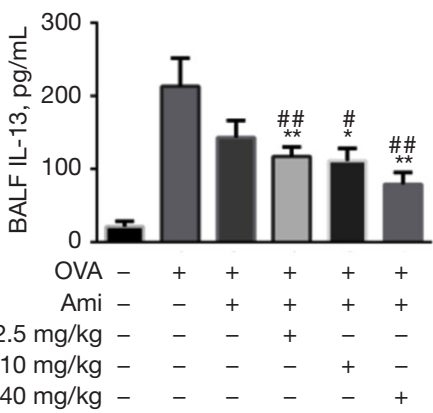

$\mathrm{F}$

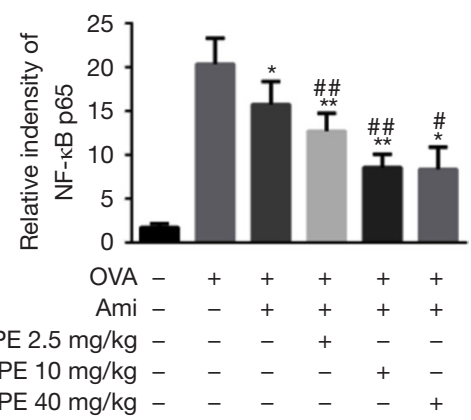

OVA + Ami + OVA + Ami + PE $(10 \mathrm{mg} / \mathrm{kg}) \quad$ PE $(40 \mathrm{mg} / \mathrm{kg})$
G

Ctrl
$\mathrm{OVA}+\mathrm{Ami}+$

OVA + Ami

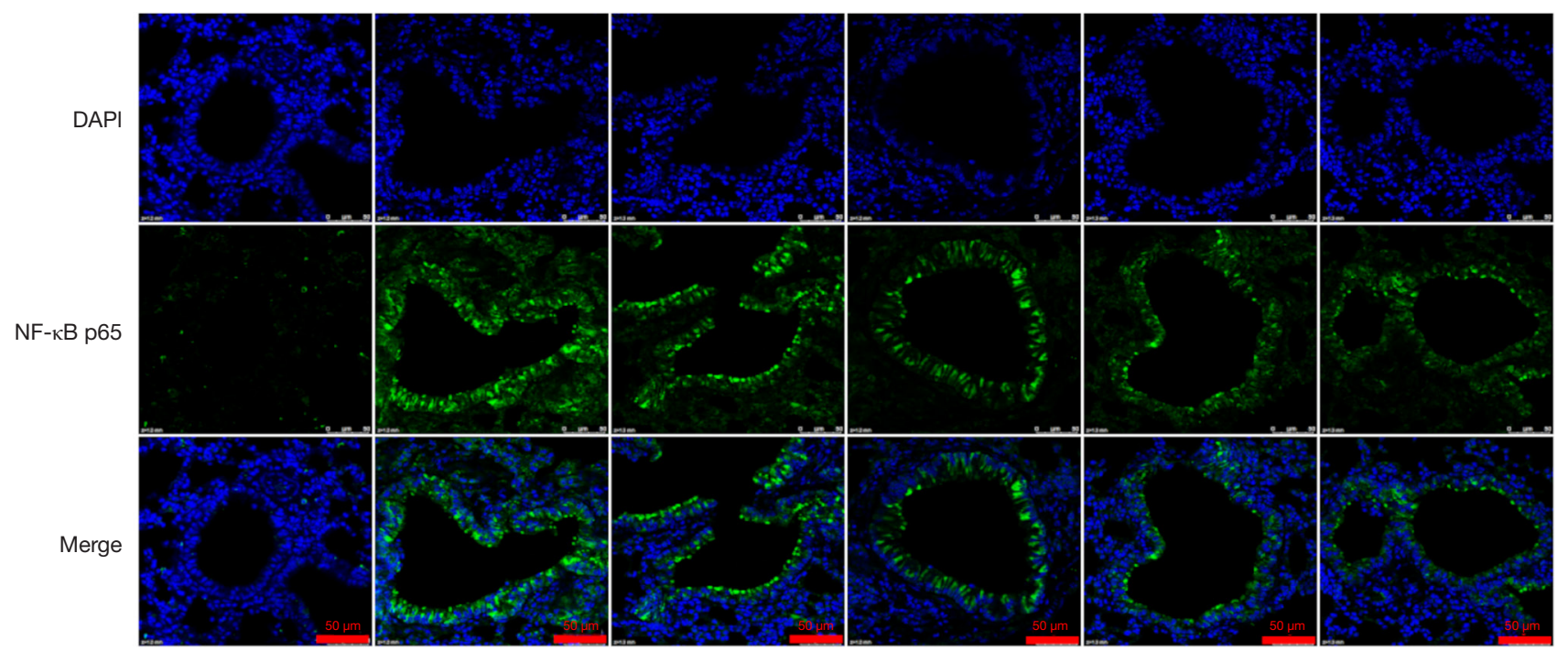



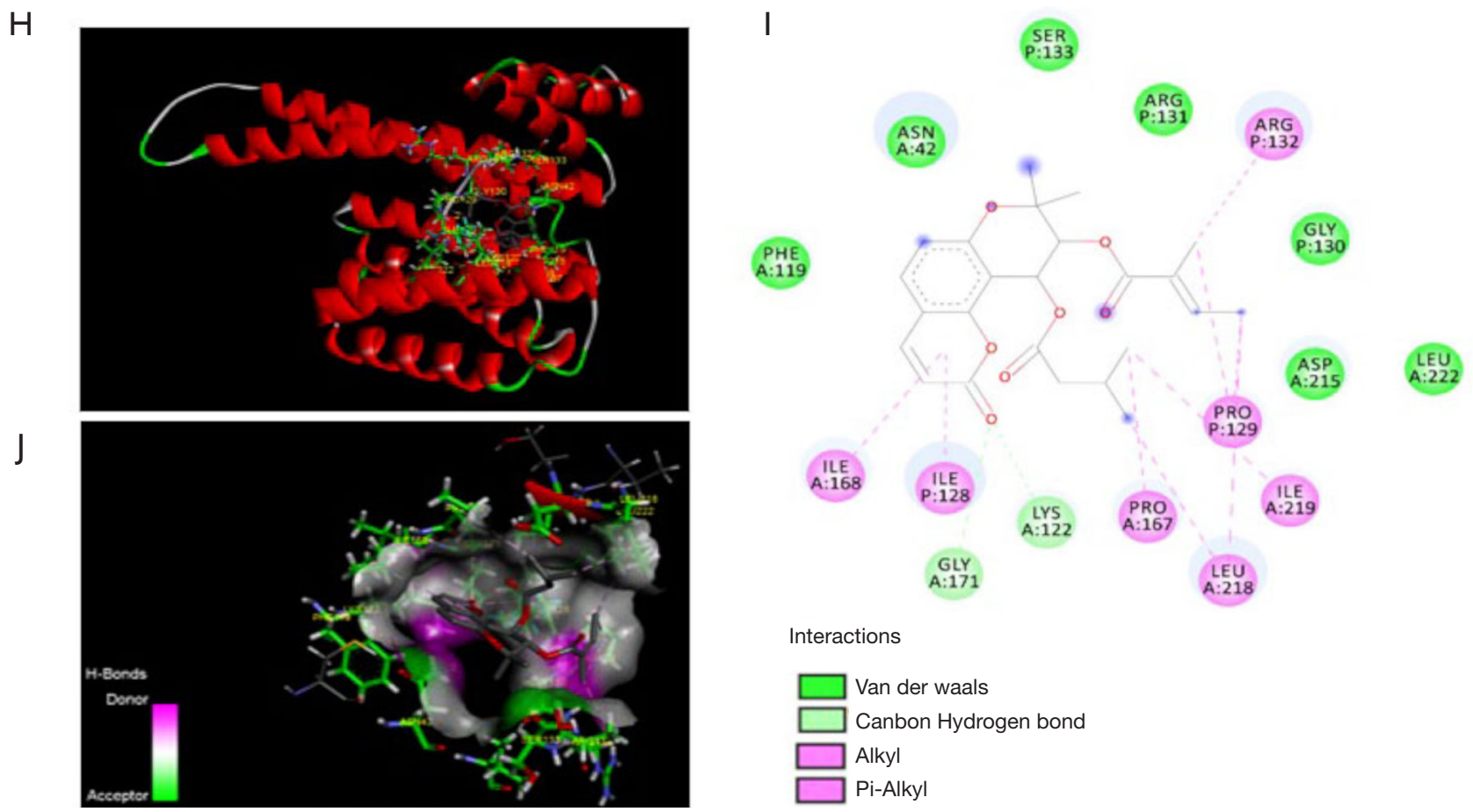

Figure 4 PE facilitates aminophylline inhibition of inflammation factors in asthmatic mice. (A-C) Concentrations of IL-4, IL-5, and IL-13 in BALF. (D,E) Concentrations of IgE and NF- $\kappa$ B p65 in serum. (F,G) Expression levels of NF- $\kappa \mathrm{B}$ p65 in the lungs and bronchi detected by immunofluorescence assay. Magnification $\times 400$, green: $\mathrm{NF}-\kappa \mathrm{B}$ p65, blue: nucleus. OVA + Ami group, OVA + Ami + PE $2.5 \mathrm{mg} / \mathrm{kg}$ group, $\mathrm{OVA}+\mathrm{Ami}+\mathrm{PE} 10 \mathrm{mg} / \mathrm{kg}$ group and OVA + Ami + PE $40 \mathrm{mg} / \mathrm{kg}$ group compared with the OVA group, ${ }^{*} \mathrm{P}<0.05,{ }^{* *} \mathrm{P}<0.01 ; \mathrm{OVA}+\mathrm{Ami}$ + PE $2.5 \mathrm{mg} / \mathrm{kg}$ group, OVA + Ami + PE $10 \mathrm{mg} / \mathrm{kg}$ group and OVA + Ami + PE $40 \mathrm{mg} / \mathrm{kg}$ group compared with the OVA + Ami group,

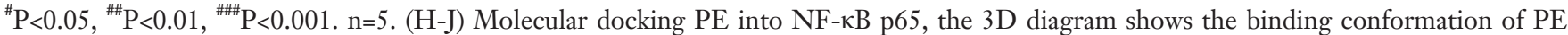

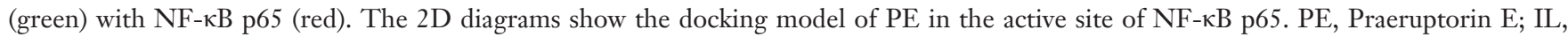

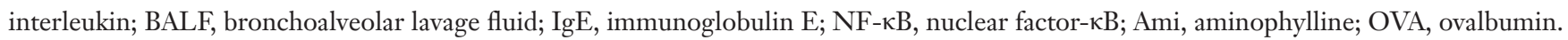

results showed that, compared with the control group, the mice in the aminophylline group had absolutely irregular heart rhythm, slow heart rates, but frequent premature ventricular beats. However, the aminophylline $+\mathrm{PE}$ group mice had regular heart rhythms, occasional premature ventricular beats, and faster ventricular rates than mice in the aminophylline-alone group (Figure $5 A, 5 B$ ). The levels of serum myocardial enzymes, such as LDH, HBD, CK-MB, $\mathrm{CK}$, and AST, were also lower than in the aminophyllinealone group (Figure $5 C-5 G$ ). These findings indicate that $\mathrm{PE}$ is beneficial in reducing the cardiac toxicity induced by aminophylline.

The primary degradant of aminophylline in the human body is theophylline, which is mainly metabolized by the hepatic drug enzymes CYP1A2, CYP2E1, and CYP3A4.
CYP1A2 is involved in the decomposition of about $90-95 \%$ of theophylline. CYP1A2 catalyzes the conversion of theophylline to 1-methylxanthine (1-MX), then 1-MX is oxidized very rapidly to $1-\mathrm{MU}$ by xanthine oxidase, while CYP3A4 and CYP2E1 catalyze the conversion of theophylline to 1,3-DMU. The accumulation of these metabolites is the main reason for the toxic effects of aminophylline (29). In the present study, LC-MS/MS was used to detect the accumulation of theophylline and its metabolites in asthmatic rats within $12 \mathrm{~h}$. The results showed that the plasma concentrations of theophylline and 1,3-DMU in the aminophylline + PE group were significantly lower than those of the aminophylline-alone group at each time investigated. Similarly, the areas under the curve (AUC) of theophylline and 1,3-DMU were also 

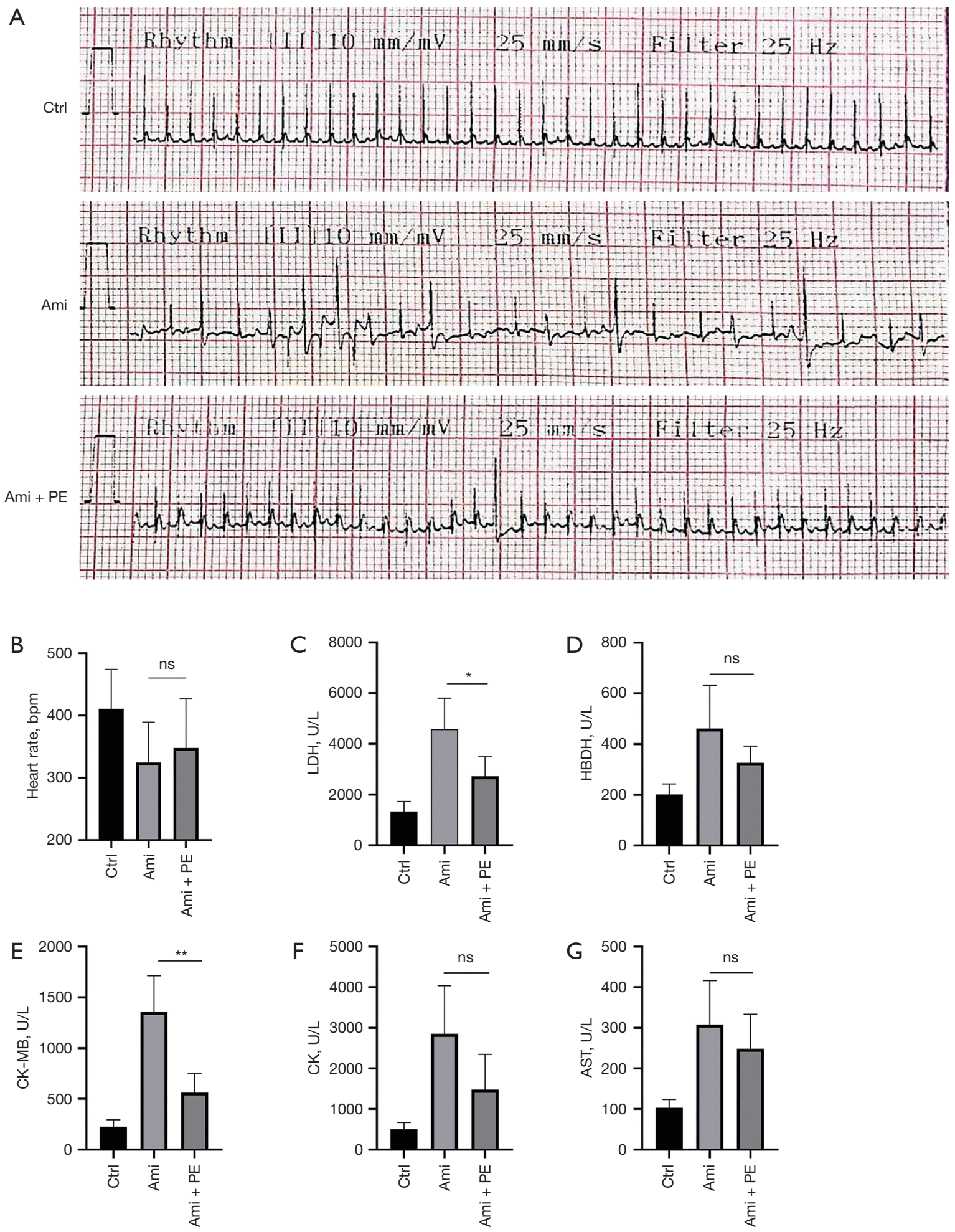

Figure $5 \mathrm{PE}$ ameliorated aminophylline cardiotoxicity in mouse. (A,B) ECG was used to analyze the electrophysiology and heart rate of mice. (C-G) ELISA detection of the contents of serum myocardial enzymes, including LDH, HBD, CK-MB, CK, and AST. *P<0.05, ${ }^{* *} \mathrm{P}<0.01$. PE, Praeruptorin E; ECG, electrocardiogram; ELISA, enzyme-linked immunosorbent assay; LDH, lactate dehydrogenase; HBD, hydroxybutyrate dehydrogenase; CK, creatine kinase; AST, aspartate aminotransferase; ctrl, control; Ami, aminophylline; ns, no significance. 
lower than in the aminophylline group, but there was no significant difference plasma concentration of 1-MU at each time point or the AUC between the two groups (Figure $6 A-6 F$ ). These results suggest that $\mathrm{PE}$ reduces the accumulation of some theophylline and 1,3-DMU, and the impairment of 1,3-DMU was prominent, but it still retained the blood concentration of most theophylline and played a pharmacological role.

\section{Effect of PE on the expression of $N F-\kappa B, P X R$, and CYP $3 A 11$ in allergic airway inflammation}

We previously found that PE is a potential ligand of PXR and that $\mathrm{PE}$ can upregulate the expression of the CYP3A4 gene through the PXR pathway (30). Therefore, we examined the effect of $\mathrm{PE}$ on the expression of NF- $\mathrm{\kappa B}$ in the lungs, and PXR, CYP3A11 (the mouse homolog of CYP3A4), CYP1A2, and CYP2E1 in the liver of asthmatic mice. In lung tissue, the mRNA and protein levels of NF- $\mathrm{KB}$ in the aminophylline group were obviously lower than in the OVA group. The expression of NF- $\mathrm{KB}$ in the aminophylline $+\mathrm{PE}(2.5,10,40 \mathrm{mg} / \mathrm{kg})$ groups was lower than in the aminophylline alone group, indicating that $\mathrm{PE}$ could reduce $\mathrm{NF}-\kappa \mathrm{B}$ activity in the lungs when used in combination with aminophylline (Figure 7A-7C). In liver tissue, the levels of mRNA and the proteins of PXR and CYP3A11 in the OVA group were lower than in the control group. The levels of PXR and CYP3A11 mRNA and protein in the aminophylline treatment group increased to a certain extent, while expression in the aminophylline $+\mathrm{PE}$ treatment group was higher than in the aminophylline-alone group. However, there was no statistically significant difference in $\mathrm{mRNA}$ and protein expression levels for CYP1A2 and CYP2E1 among the treatment groups (Figure $7 A-7 C$ ). These findings indicate that $\mathrm{PE}$ can positively regulate the expressions of NF- $\mathrm{kB}, \mathrm{PXR}$, and CYP3A11 in vivo to promote the elimination of theophylline and 1,3-DMU.

\section{$P E$ inbibits $N F-\kappa B$ activation and regulates $P X R$ and CYP3A4 overexpression in $L-02$ cells}

Human L-02 cells were used to clarify the mechanism of the synergistic and detoxifying effects of PE on aminophylline. First, LPS (100 ng/mL)-induced L-02 cells were treated with $60 \mu \mathrm{M} \mathrm{PE}$. The results showed that $\mathrm{PE}$ reduced the expression of $\mathrm{NF}-\mathrm{\kappa B}$, promoted the expression of PXR and CYP3A4, and reversed the inhibitory effect on inflammation of PXR and CYP3A4 (Figure 7D,7E). Next, we established L-02 cell models under different growth states by LPS induction or siRNA interference, and further verified the mechanism of $\mathrm{PE}$ co-administered with aminophylline. Under the condition of only LPS-induced inflammation, the expression of NF- $\kappa \mathrm{B}$ in the aminophylline $+\mathrm{PE}$ group was lower than in the aminophylline group, and the expression of PXR and CYP3A4 was higher than in the aminophylline group. The findings indicated that aminophylline $+\mathrm{PE}$ could reduce the expression of NF$\kappa \mathrm{B}$ and increase the expression of PXR and CYP3A4 in the inflammatory state. When the expression of PXR was knocked down by siRNA under inflammation, the effect of $\mathrm{PE}$ on the synergized reduction of $\mathrm{NF}-\kappa \mathrm{B}$ expression was reduced, as well as its effects on the expression of PXR and CYP3A4 (Figure $7 F-7 H$ ). Although the results indicated that inflammation could inhibit the expression of PXR, whether NF- $\kappa B$ had an inhibitory effect on PXR still remains to be verified unequivocally. Therefore, ChIP experiments were conducted and the results revealed that chromatin was mainly concentrated at about $500 \mathrm{bp}$ and that PXR was expressed in both the input and ChIP DNA samples, suggesting that NF- $\mathrm{KB}$ was enriched at the binding site of the PXR promoter region and that $\mathrm{PE}$ could reduce the enrichment of the NF- $\mathrm{BB}$ and PXR promoter (Figure 7I,7f). Therefore, the findings indicate that PE could reduce the toxicity and enhance the efficacy of aminophylline through

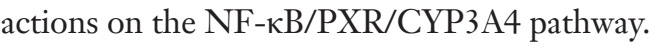

\section{Discussion}

As the 14th most common chronic disease in the world, asthma not only seriously affects patients' physical and mental health, but also brings a heavy economic burden to families, countries, and healthcare services (31). Multiple inflammatory cells and factors play key roles in the development of asthma. During the process of infiltration and aggregation of inflammatory cells, such as eosinophils, into the lungs and trachea, a large number of cytokines and inflammatory mediators is secreted. These are involved in chemotaxis, leading to the contraction of airway smooth muscle and increased mucus secretion and mucosal edema (32). The Th2 cytokines, IL-4, IL-5, and IL-13, and eosinophil chemokines are also major participants. IL-4 is one of the most important cytokines regulating Th2 inflammation, which can induce the maturation of B cells and promote the transformation of $\operatorname{IgG}$ into $\operatorname{IgE}(33)$. 
A

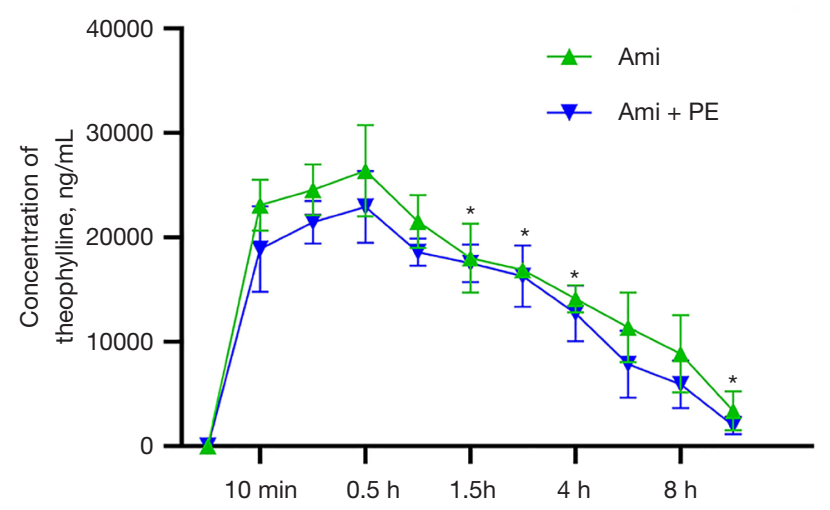

C

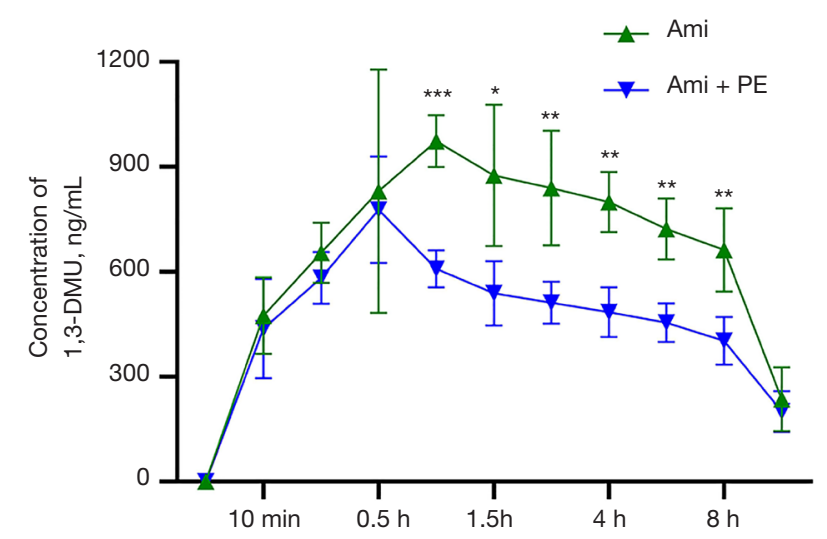

$\mathrm{E}$

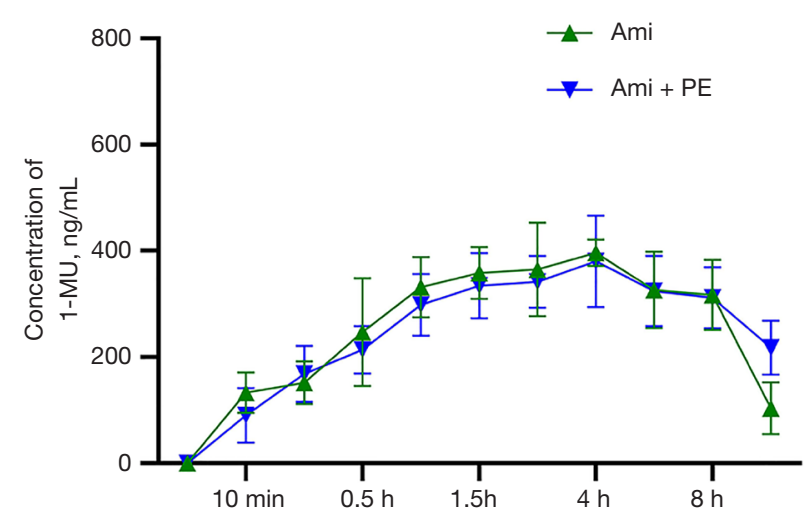

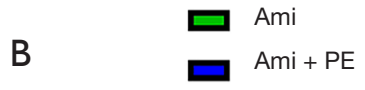
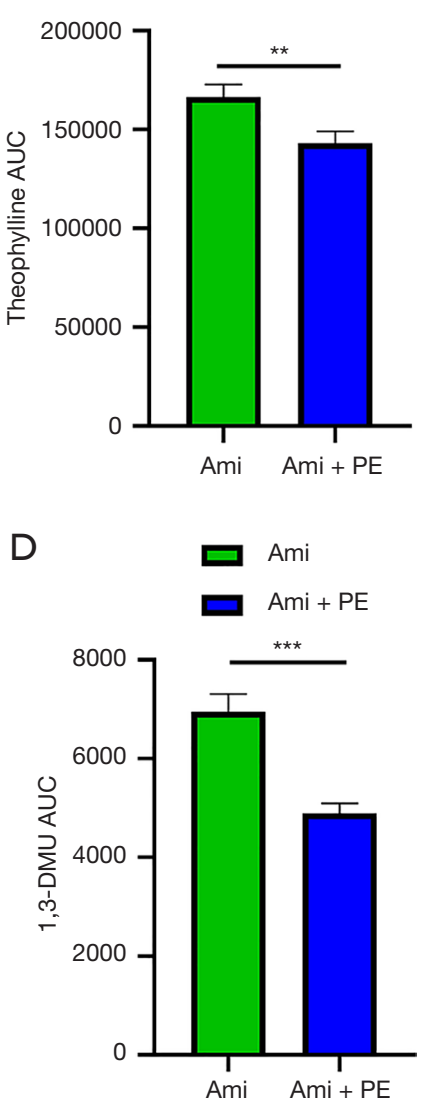

$\mathrm{F}$

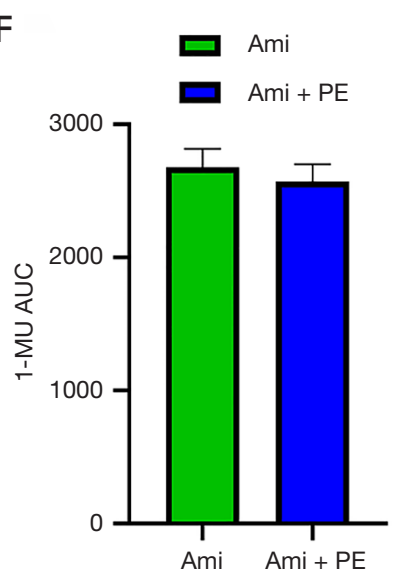

Figure 6 PE promotes metabolism of Ami metabolites in in asthma rats. (A,C,E) Plasma concentration of theophylline, 1,3-DMU, and 1-MU in asthmatic rats in a period of $12 \mathrm{~h}$ determined by LC-MS/MS analysis. (B,D,F) AUC of theophylline, 1,3-DMU, and 1-MU by GraphPad Prism 8 analysis. ${ }^{*} \mathrm{P}<0.05 ;{ }^{* *} \mathrm{P}<0.01 ;{ }^{* * *} \mathrm{P}<0.001 . \mathrm{n}=4$. $\mathrm{PE}$, Praeruptorin $\mathrm{E}$; Ami, aminophylline; 1,3-DMU, 1,3-dimethyluric acid; 1-MU, 1-methyluric acid; LC-MS/MS, liquid chromatography-tandem mass spectrometry; AUC, area under the curve; SD, Sprague-Dawley; OVA, ovalbumin. 
A

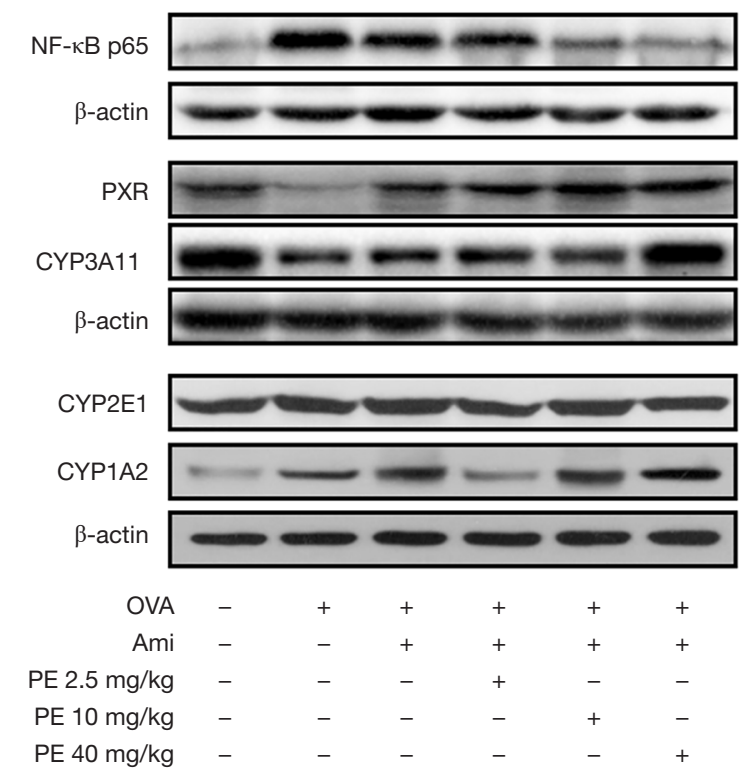

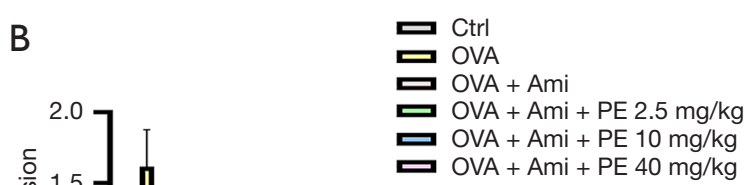

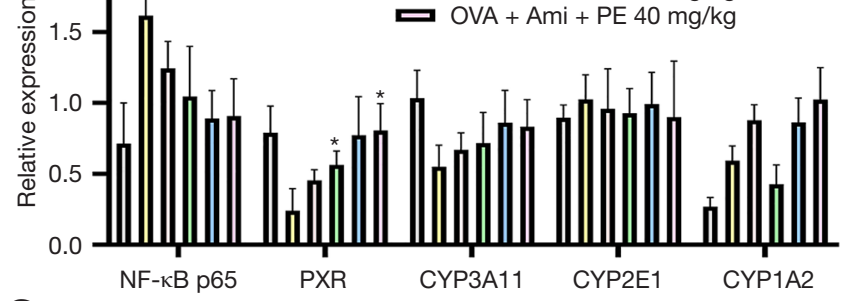

C

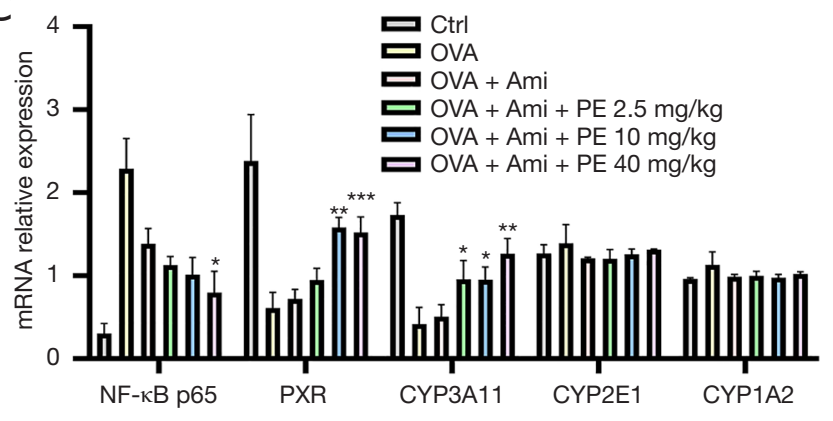

D

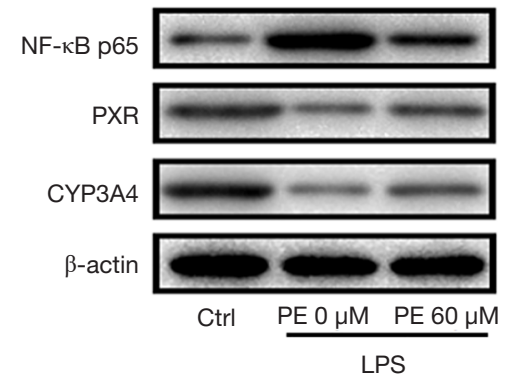

F
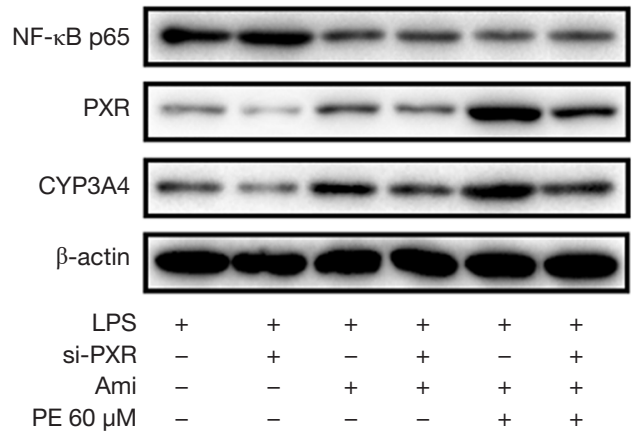

E

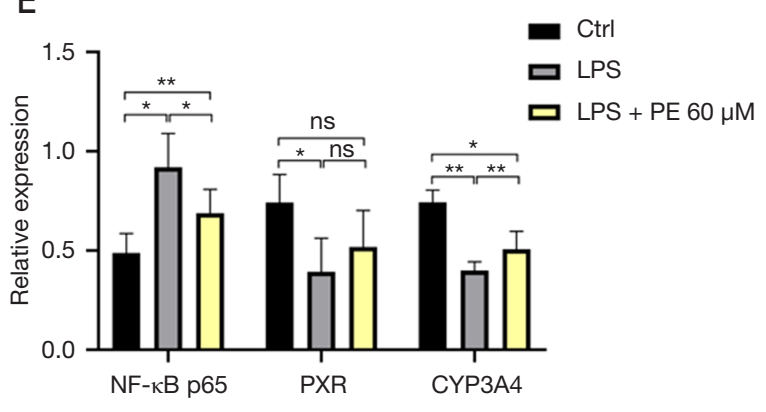

G

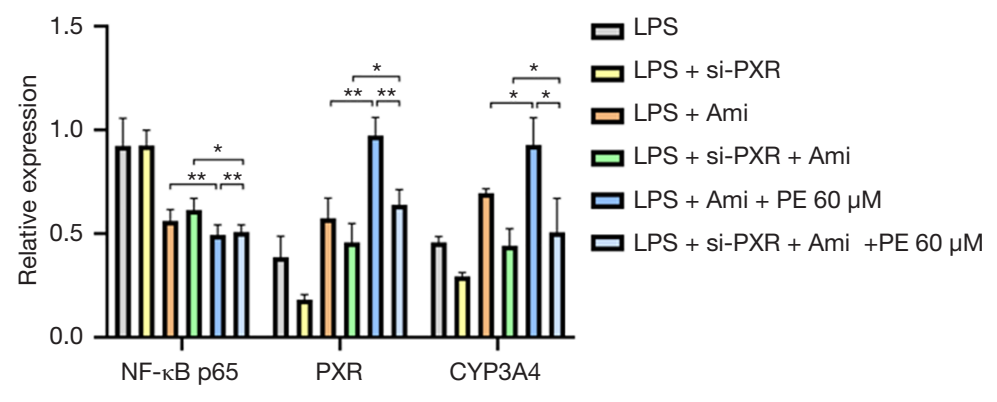



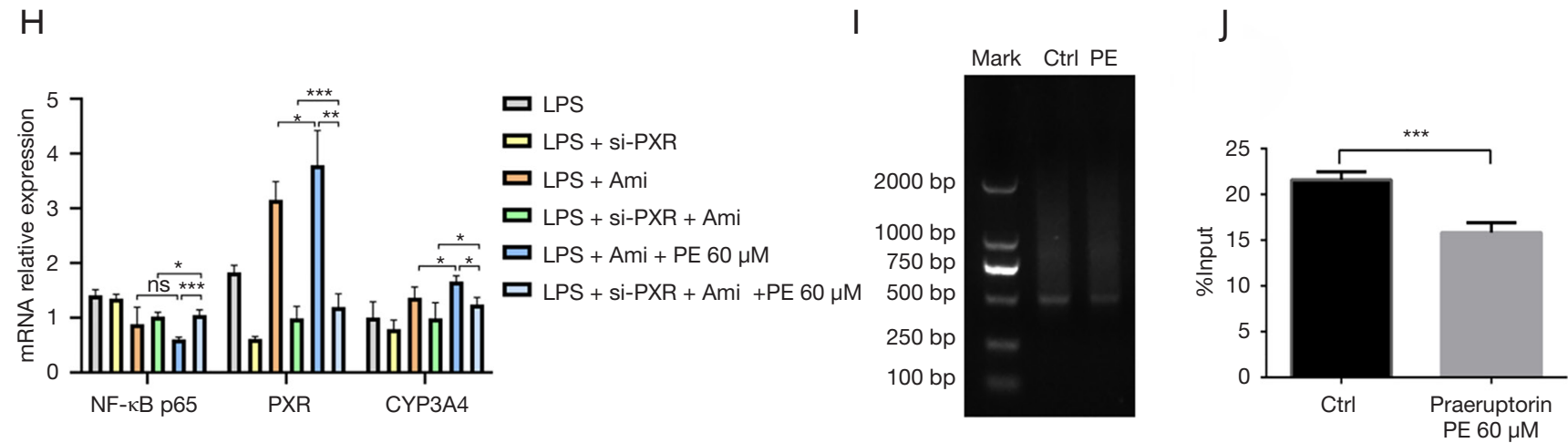

Figure $7 \mathrm{PE}$ attenuates toxicity and promotes the efficacy of Ami anti-asthma activity via NF- $\mathrm{B} / \mathrm{PXR} / \mathrm{CYP} 3 \mathrm{~A} 4$ pathways. (A-C) Expression levels of NF- $\mathrm{B}$ p 65 in the lungs and PXR, CYP3A11, CYP1A2, CYP2E1 in the liver of asthmatic mice determined by Western blotting and reverse transcription PCR. OVA + Ami + PE $2.5 \mathrm{mg} / \mathrm{kg}$ group, OVA + Ami + PE $10 \mathrm{mg} / \mathrm{kg}$ group and OVA + Ami + PE $40 \mathrm{mg} / \mathrm{kg}$ group compared with the OVA + Ami group, ${ }^{*} \mathrm{P}<0.05,{ }^{* *} \mathrm{P}<0.01,{ }^{* * *} \mathrm{P}<0.001 . \mathrm{n}=5$. (D,E) After the LPS-induced inflammatory state of L-02 cells was established, the expression of NF- $\mathrm{KB}$ p65, PXR, and CYP3A4 in L-02 cells was detected by Western blotting after PE treatment for 24 h. (F-H) Under LPS-induced inflammation and si-PXR effected, the L-02 cells were treated with Ami and PE for 24 h, Western blotting and reverse transcription PCR were used to detect the expression of NF- $\mathrm{B}$ p65, PXR, and CYP3A4. (I,J) Degree of enrichment of NF- $\kappa \mathrm{B}$ p65 and PXR promoters detected by ChIP assay. ${ }^{*} \mathrm{P}<0.05,{ }^{* *} \mathrm{P}<0.01,{ }^{* * *} \mathrm{P}<0.001$. Data are representative of 3 independent experiments. PE, Praeruptorin E; Ami, aminophylline; NF- $\kappa$, nuclear factor- $\kappa \mathrm{B}$; PXR, pregnane X receptor; CYP3A4, cytochrome P450 3A; PCR, polymerase chain reaction; LPS, lipopolysaccharide; ChIP, chromatin immunoprecipitation; ctrl, control; OVA, ovalbumin; ns, no significance.

IL-5 is important for the differentiation and maturation of eosinophils and has a vital role in the allergen-induced eosinophilic airway inflammation (34). IL-5 also enhances IL-4-induced IgE production. IL-13 promotes B-cell differentiation and can directly induce airway inflammation and the altitude reaction (35).

Theophylline is a derivative of methylxanthine and has significant anti-asthmatic activity, a low price, and is suitable for administration in both children and adults. As a non-selective phosphodiesterase inhibitor and adenosine receptor antagonist, the mechanism of its anti-asthmatic action is inhibition of the production of adhesion molecules and cytokines, therefore preventing airway aggregation of inflammatory cells, the expression of inflammatory mediators and cytokines, and Th 2 transcription and translation (36). Moreover, airway smooth muscle relaxation is another pharmacodynamic effect of aminophylline. However, the plasma concentration of aminophylline should reach $10-20 \mathrm{mg} / \mathrm{L}$ before it becomes effective, making the plasma drug concentration close to its toxic concentration. When the concentration is $>20 \mathrm{mg} / \mathrm{L}$, some patients could exhibit toxic symptoms that often present as severe cardiotoxicity and central nervous system disturbances. When the drug concentration exceeds $40 \mathrm{mg} / \mathrm{L}$, patients develop symptoms of aminophylline toxicity, which can be life-threatening $(37,38)$. Therefore, reducing the blood drug concentration of aminophylline and its metabolites does not only lower the incidence of toxicity and side-effects, but also exerts a significant anti-inflammatory effect.

Peucedanum praeruptorum Dunn is the main medicinal material of Chinese medicine used for the relief of cough and asthma symptoms. Previous studies have shown that various active components of Peucedanum praeruptorum Dunn have anti-inflammatory effects $(23,39,40)$. Therefore, we also speculated that $\mathrm{PE}$, its main active component, would enhance the role of aminophylline in the treatment of asthma. In the present study, we found that PE combined with aminophylline could promote aminophylline reduction in the infiltration of inflammatory cells, mucus secretion, and collagen cell fibrosis in the lungs and bronchi of asthmatic mice and repair their physiological structures. It also acts to inhibit the expression levels of Th2 cytokines 
IL-4, IL-5, and IL-13, and IgE and NK-кB p65. These findings indicate that $\mathrm{PE}$ could play a synergistic role with aminophylline. Furthermore, our results showed that $\mathrm{PE}$ can reduce the plasma concentration of theophylline in asthmatic rats to a significant extent and reduce the accumulation of 1,3-DMU. Interestingly, the changes in the plasma concentration of 1-MU were not significant. According to previous reports (41), it has been reported that $\mathrm{PE}$ does not reduce aminophylline metabolite levels through the CYP1A2 metabolic pathway.

$\mathrm{NF}-\kappa \mathrm{B}$ is a key transcription factor in various pathological conditions. When stimulated by an antigen, inhibitor of $\mathrm{NF}-\kappa \mathrm{B}(\mathrm{I} \kappa \mathrm{B})$ is separated from NF- $\kappa \mathrm{B}$ p 65 and phosphorylated. NF- $\mathrm{\kappa B}$ p 65 is translocated from the cytoplasm into the nucleus, facilitating the synthesis and release of pro-inflammatory cytokines $(42,43)$. NF- $\kappa \mathrm{B}$ can regulate Th2 cell differentiation and Th2 cytokine expression in allergic asthma. Inhibiting the activity of NF$\kappa \mathrm{B}$ is an effective way to treat asthma $(44,45)$. Our results have shown that $\mathrm{PE}$ in combination with aminophylline reduces the expression of $\mathrm{NF}-\kappa \mathrm{B}$ p 65 in the lungs of asthmatic rats and decreases the expression of LPSinduced NF- $\kappa \mathrm{B}$ in vitro. Therefore, we deduced that $\mathrm{PE}$ can cooperate with aminophylline to inhibit the NF- $\mathrm{kB}$ pathway and reduce Th2 cytokine secretion, thereby ameliorating airway inflammation, mucus secretion, and fibrosis in asthmatic mice.

PXR belongs to the nuclear receptor superfamily of NR1I, and participates in the bioconversion of many endogenous and exogenous chemicals. PXR is composed of a ligand binding domain (LBD) and a DNA binding domain. When the exogenous molecule enters a cell, it directly binds to the intracellular LBD to form the receptor-ligand complex, and then binds to the retinoid X receptor (RXR) to form the PXR/RXR heterodimer (46-48). Asthma is a chronic inflammatory disease of the airways that involves the activity of many cytokines. Therefore, asthma is often associated with the increased expression of cytokines, such as NF- $\kappa \mathrm{B}$. A large amount of activated NF- $\kappa \mathrm{B}$ binds to the reaction element of RXR on the heterodimer of PXR/RXR through its p65 subunit in the nucleus, thereby reducing the binding of the PXR/RXR dimer to the promoter of CYP3A4, and finally downregulates the drug-metabolizing enzymes, such as CYP3A4, by inhibiting the transcriptional activity of PXR $(26,49,50)$. When PXR expression in cells is increased, it binds to p65 in the cytoplasm, prevents p65 nuclear translocation, and weakens the role of NF- $\mathrm{NB}$ in activating downstream pro-inflammatory genes. Therefore, PXR and NF- $\mathrm{BB}$ have a 2-way regulatory effect $(51,52)$. It was found that after transfection of human PXR into mice with knocked out $P X R$ genes, human specific inducers could induce CYP3A (53), indicating that the PXR/RXR dimer could bind to the PXR response element on the CYP3A gene promoter and induce the expression of the CYP3A gene. In our previous study, we also found that PE could upregulate the expression of the CYP3A4 gene through the PXR pathway (30). In the present study, PE increased the expression of PXR and CYP3A4 in asthmatic mice, but there was no obvious effect on the metabolic enzymes, CYP1A2 and CYP2E1, indicating that CYP3A4 metabolic enzymes were the main target for PE. In vitro results demonstrated that PE could also reverse the inhibitory effects on inflammation of PXR and CYP3A4. When PXR expression was reduced with siRNA interference, the synergistic effect of PE was weakened. In addition, the ChIP assay verified that NF- $\mathrm{KB}$ was enriched at the binding site of the PXR promoter region and that $\mathrm{PE}$ could reduce the enrichment of the NF- $\kappa \mathrm{B}$ and PXR promoter, weakening the inhibition of NF- $\kappa \mathrm{B}$ on PXR. In addition, some studies have found that PE can play an anti-inflammatory effect by inhibiting STAT3 signaling pathway (54), and STAT3 also has a regulatory effect on PXR (55), which means that PE may also produce attenuated and synergistic effects through STAT3/PXR signaling axis. In the future, we should also explore another role.

\section{Conclusions}

The findings of the present study confirmed that PE could enhance aminophylline activity to reduce the infiltration of inflammatory cells, mucus secretion, and fibrosis in the lungs of asthmatic mice; inhibit the expression of inflammatory factors IL-4, IL-5, IL-13, IgE, and NF$\kappa \mathrm{B}$; and have a synergistic effect with aminophylline to treat asthma. It was also found that PE could reduce the plasma concentration of theophylline, 1,3-DMU and play a role in reducing toxicity. During the in vitro experiments, $\mathrm{PE}$ was found to assist aminophylline in reducing the expression of $\mathrm{NF}-\kappa \mathrm{B}$ and in reversing the expression of PXR and CYP3A4, indicating that PE is involved in reducing toxicity and enhancing its efficacy through the bidirectional regulation of NF- $\mathrm{kB} / \mathrm{PXR} / \mathrm{CYP} 3 \mathrm{~A} 4$ (Figure 8). 


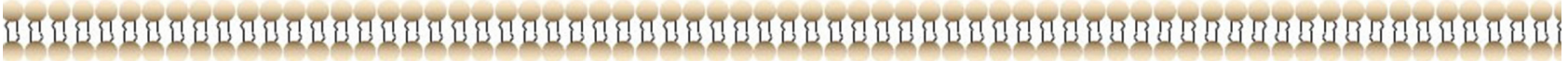

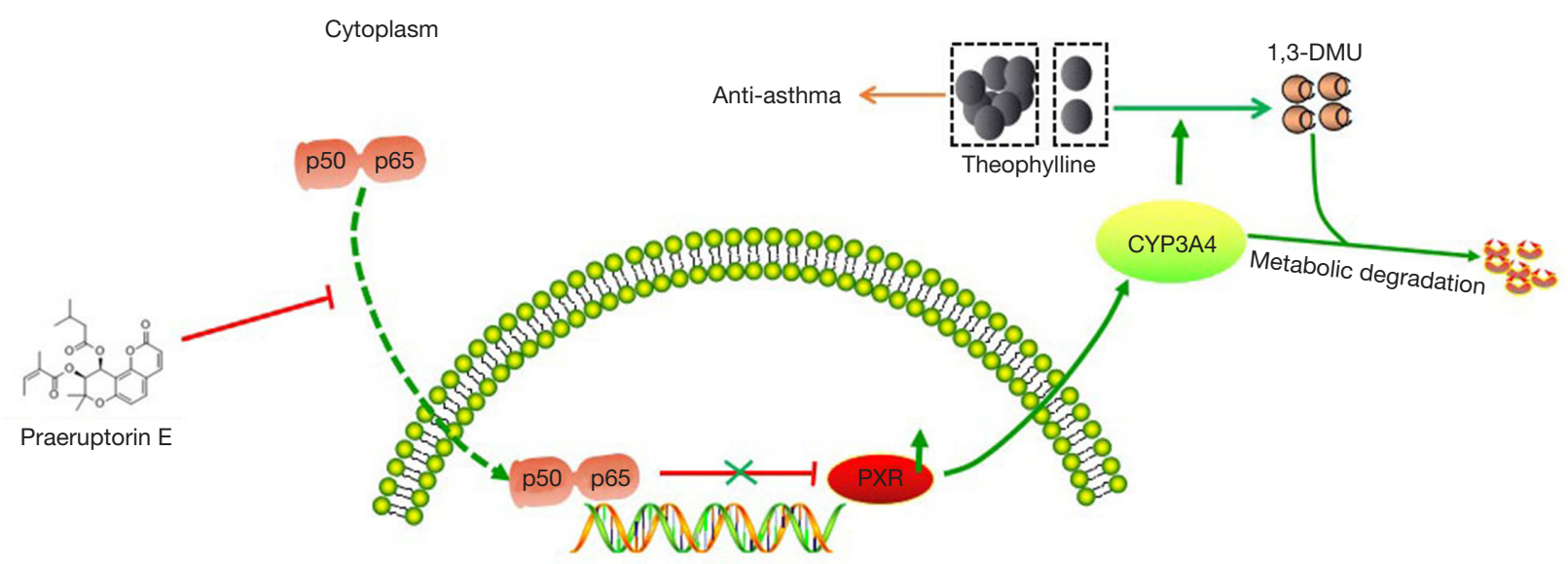

Inflammatory state of asthma

Figure 8 In the inflammatory state of asthma, PE can inhibit the expression of $\mathrm{NF}-\kappa \mathrm{B}$ p 65 , reduce the inhibitory effect on PXR, and promote the expression of CYP3A4, CYP3A4 promotes the metabolism of theophylline and 1,3-DMU. PE can enhance the anti-asthma effect of aminophylline, while also reducing the toxic effect caused by theophylline by targeting the NF- $\mathrm{BB} / \mathrm{PXR} / \mathrm{CYP} 3 \mathrm{~A} 11$ axis. PE,

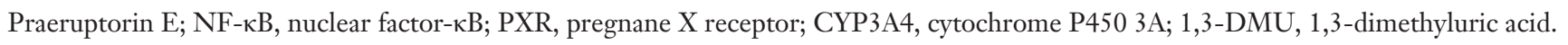

Taken together, these findings indicate that Peucedanum praeruptorum Dunn is a promising herbal medicine that will benefit asthmatics treated with theophylline. In the future, we will continue to execute in-depth studies, including studies on improving the mechanism of PE, safety experiments, pharmacological effects and primate studies.

\section{Acknowledgments}

Funding: This work was supported by grants from the National Natural Science Foundation of China (Nos. 81403006, 81760674, 82060678); Research Unit of Island Emergency Medicine, Chinese Academy of Medical Sciences (No. 2019RU013).

\section{Footnote}

Reporting Checklist: The authors have completed the ARRIVE reporting checklist. Available at https://atm. amegroups.com/article/view/10.21037/atm-22-386/rc

Data Sharing Statement: Available at https://atm.amegroups. com/article/view/10.21037/atm-22-386/dss
Conflicts of Interest: All authors have completed the ICMJE uniform disclosure form (available at https://atm. amegroups.com/article/view/10.21037/atm-22-386/coif). The authors have no conflicts of interest to declare.

Ethical Statement: The authors are accountable for all aspects of the work in ensuring that questions related to the accuracy or integrity of any part of the work are appropriately investigated and resolved. All experiments were approved by the Institutional Animal Care and Treatment Committee of Hainan Medical University (Ratified on October 16, 2017), in compliance with Guidelines for the Humane Treatment of Laboratory Animals (Ministry of Science and Technology of the People's Republic of China; policy No. 2006398).

Open Access Statement: This is an Open Access article distributed in accordance with the Creative Commons Attribution-NonCommercial-NoDerivs 4.0 International License (CC BY-NC-ND 4.0), which permits the noncommercial replication and distribution of the article with the strict proviso that no changes or edits are made and the original work is properly cited (including links to both the 
formal publication through the relevant DOI and the license). See: https://creativecommons.org/licenses/by-nc-nd/4.0/.

\section{References}

1. Kim TH, Park YM, Ryu SW, et al. Receptor Interacting Protein 2 (RIP2) Is Dispensable for OVA-Induced Airway Inflammation in Mice. Allergy Asthma Immunol Res 2014;6:163-8.

2. Bousquet J, Mantzouranis E, Cruz AA, et al. Uniform definition of asthma severity, control, and exacerbations: document presented for the World Health Organization Consultation on Severe Asthma. J Allergy Clin Immunol 2010;126:926-38.

3. Nakajima H, Takatsu K. Role of cytokines in allergic airway inflammation. Int Arch Allergy Immunol 2007;142:265-73.

4. Li BW, Hendriks RW. Group 2 innate lymphoid cells in lung inflammation. Immunology 2013;140:281-7.

5. Licona-Limón P, Kim LK, Palm NW, et al. TH2, allergy and group 2 innate lymphoid cells. Nat Immunol 2013;14:536-42.

6. Maselli DJ, Hardin M, Christenson SA, et al. Clinical Approach to the Therapy of Asthma-COPD Overlap. Chest 2019;155:168-77.

7. Ernst E. Spinal manipulation for asthma: a systematic review of randomised clinical trials. Respir Med 2009;103:1791-5.

8. Eason J, Markowe HL. Aminophylline toxicity--how many hospital asthma deaths does it cause? Respir Med 1989;83:219-26.

9. Starakis I, Starakis I, Lekkou A, et al. Drug-induced cardiotoxicity due to aminophylline treatment: a case report. Curr Ther Res Clin Exp 2003;64:367-74.

10. Kubo $M$, Odajima $Y$, Ishizaki $T$, et al. Intraindividual changes in theophylline clearance during constant aminophylline infusion in children with acute asthma. J Pediatr 1986;108:1011-5.

11. Barnes PJ. Pathophysiology of allergic inflammation. Immunol Rev 2011;242:31-50.

12. Berkman N, Krishnan VL, Gilbey T, et al. Expression of RANTES mRNA and protein in airways of patients with mild asthma. Am J Respir Crit Care Med 1996;154:1804-11.

13. Grilli M, Chiu JJ, Lenardo MJ. NF-kappa B and Rel: participants in a multiform transcriptional regulatory system. Int Rev Cytol 1993;143:1-62.

14. John AE, Zhu YM, Brightling CE, et al. Human airway smooth muscle cells from asthmatic individuals have CXCL8 hypersecretion due to increased NF-kappa B p65, C/EBP beta, and RNA polymerase II binding to the CXCL8 promoter. J Immunol 2009;183:4682-92.

15. Scarino A, Noël A, Renzi PM, et al. Impact of emerging pollutants on pulmonary inflammation in asthmatic rats: ethanol vapors and agglomerated $\mathrm{TiO} 2$ nanoparticles. Inhal Toxicol 2012;24:528-38.

16. Chae JW, Baek IH, Kwon KI. Effect of decursin on the pharmacokinetics of theophylline and its metabolites in rats. J Ethnopharmacol 2012;144:248-54.

17. Zhou C, Tabb MM, Nelson EL, et al. Mutual repression between steroid and xenobiotic receptor and NF-kappaB signaling pathways links xenobiotic metabolism and inflammation. J Clin Invest 2006;116:2280-9.

18. Goodwin B, Redinbo MR, Kliewer SA. Regulation of cyp3a gene transcription by the pregnane $\mathrm{x}$ receptor. Annu Rev Pharmacol Toxicol 2002;42:1-23.

19. Shah YM, Ma X, Morimura K, et al. Pregnane X receptor activation ameliorates DSS-induced inflammatory bowel disease via inhibition of NF-kappaB target gene expression. Am J Physiol Gastrointest Liver Physiol 2007;292:G1114-22.

20. Wenjie W, Houqing L, Liming S, et al. Effects of praeruptorin $\mathrm{C}$ on blood pressure and expression of phospholamban in spontaneously hypertensive rats. Phytomedicine 2014;21:195-8.

21. Shen X, Chen G, Zhu G, et al. (+/-)-3'-O, 4'-O-dicynnamoyl-cis-khellactone, a derivative of (+/-)-praeruptorin A, reverses P-glycoprotein mediated multidrug resistance in cancer cells. Bioorg Med Chem 2006;14:7138-45.

22. Liu X, Chin JF, Qu X, et al. The Beneficial Effect of Praeruptorin C on Osteoporotic Bone in Ovariectomized Mice via Suppression of Osteoclast Formation and Bone Resorption. Front Pharmacol 2017;8:627.

23. Xiong Y, Wang J, Wu F, et al. Effects of ( \pm )-praeruptorin A on airway inflammation, airway hyperresponsiveness and NF- $\mathrm{KB}$ signaling pathway in a mouse model of allergic airway disease. Eur J Pharmacol 2012;683:316-24.

24. Huang L, Huang M, Li YH, et al. Up-regulatation of CYP3A expression through pregnent $X$ receptor by praeruptorin $\mathrm{D}$ isolated from Peucedanum praeruptorum Dunn. J Ethnopharmacol 2013;148:596-602. 
25. Huang L, Bi HC, Li YH, et al. Regulation of human pregnane $\mathrm{X}$ receptor and its target gene cytochrome $\mathrm{P} 450$ $3 \mathrm{~A}$ by praeruptorin A isolated from the herbal medicine Peucedanum praeruptorum. Planta Med 2013;79:1509-15.

26. Huang L, Wu Q, Li YH, et al. PXR-Mediated Upregulation of CYP3A Expression by Herb Compound Praeruptorin C from Peucedanum praeruptorum Dunn. Evid Based Complement Alternat Med 2013;2013:156574.

27. Jin H, Luo Q, Zheng Y, et al. CD4+CD25+Foxp3+T cells contribute to the antiasthmatic effects of Astragalus membranaceus extract in a rat model of asthma. Int Immunopharmacol 2013;15:42-9.

28. Whitehurst VE, Joseph X, Alleva FR, et al. Enhancement of acute myocardial lesions by asthma drugs in rats. Toxicol Pathol 1994;22:72-6.

29. Sohn JA, Kim HS, Oh J, et al. Prediction of serum theophylline concentrations and cytochrome P450 1A2 activity by analyzing urinary metabolites in preterm infants. Br J Clin Pharmacol 2017;83:1279-86.

30. Liu YH, Mo SL, Bi HC, et al. Regulation of human pregnane $\mathrm{X}$ receptor and its target gene cytochrome P450 3A4 by Chinese herbal compounds and a molecular docking study. Xenobiotica 2011;41:259-80.

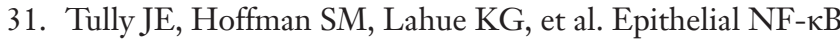
orchestrates house dust mite-induced airway inflammation, hyperresponsiveness, and fibrotic remodeling. J Immunol 2013;191:5811-21.

32. Agrawal DK, Shao Z. Pathogenesis of allergic airway inflammation. Curr Allergy Asthma Rep 2010;10:39-48.

33. Elias JA, Lee CG, Zheng T, et al. New insights into the pathogenesis of asthma. J Clin Invest 2003;111:291-7.

34. Renz H, Enssle K, Lauffer L, et al. Inhibition of allergeninduced IgE and IgG1 production by soluble IL-4 receptor. Int Arch Allergy Immunol 1995;106:46-54.

35. Halim TY, Krauss RH, Sun AC, et al. Lung natural helper cells are a critical source of Th2 cell-type cytokines in protease allergen-induced airway inflammation. Immunity 2012;36:451-63.

36. Littenberg B. Aminophylline treatment in severe, acute asthma. A meta-analysis. JAMA 1988;259:1678-84.

37. Barnes PJ. Theophylline. Am J Respir Crit Care Med 2013;188:901-6.

38. McEvoy GK. Dose adjustment in renal impairment: response from AHFS Drug Information. BMJ 2005;331:293.

39. Yu PJ, Ci W, Wang GF, et al. Praeruptorin A inhibits lipopolysaccharide-induced inflammatory response in murine macrophages through inhibition of $\mathrm{NF}-\kappa \mathrm{B}$ pathway activation. Phytother Res 2011;25:550-6.

40. Yu PJ, Li JR, Zhu ZG, et al. Praeruptorin D and E attenuate lipopolysaccharide/hydrochloric acid induced acute lung injury in mice. Eur J Pharmacol 2013;710:39-48.

41. Jing WH, Song YL, Yan R, et al. Identification of cytochrome $\mathrm{P} 450$ isoenzymes involved in metabolism of (+)-praeruptorin A, a calcium channel blocker, by human liver microsomes using ultra high-performance liquid chromatography coupled with tandem mass spectrometry. J Pharm Biomed Anal 2013;77:175-88.

42. Van Antwerp DJ, Martin SJ, Kafri T, et al. Suppression of TNF-alpha-induced apoptosis by NF-kappaB. Science 1996;274:787-9.

43. Li Q, Verma IM. NF-kappaB regulation in the immune system. Nat Rev Immunol 2002;2:725-34.

44. Xia YF, Ye BQ, Li YD, et al. Andrographolide attenuates inflammation by inhibition of NF-kappa B activation through covalent modification of reduced cysteine 62 of p50. J Immunol 2004;173:4207-17.

45. Das J, Chen CH, Yang L, et al. A critical role for NFkappa B in GATA3 expression and TH2 differentiation in allergic airway inflammation. Nat Immunol 2001;2:45-50.

46. Willson TM, Kliewer SA. PXR, CAR and drug metabolism. Nat Rev Drug Discov 2002;1:259-66.

47. Kliewer SA, Moore JT, Wade L, et al. An orphan nuclear receptor activated by pregnanes defines a novel steroid signaling pathway. Cell 1998;92:73-82.

48. Yan J, Xie W. A brief history of the discovery of PXR and CAR as xenobiotic receptors. Acta Pharm Sin B 2016;6:450-2.

49. Hogle BC, Guan X, Folan MM, et al. PXR as a mediator of herb-drug interaction. J Food Drug Anal 2018;26:S26-31.

50. Xie W, Barwick JL, Downes M, et al. Humanized xenobiotic response in mice expressing nuclear receptor SXR. Nature 2000;406:435-9.

51. Zhang J, Cao L, Wang H, et al. Ginsenosides Regulate PXR/NF- $\kappa$ B Signaling and Attenuate Dextran Sulfate Sodium-Induced Colitis. Drug Metab Dispos 2015;43:1181-9.

52. Lv C, Huang L. Xenobiotic receptors in mediating the effect of sepsis on drug metabolism. Acta Pharm Sin B 2020;10:33-41.

53. Zhao Y, Zhang CW, Zhou WJ, et al. Is there a role of TNFR1 in acute lung injury cases associated with extracorporeal circulation? J Zhejiang Univ Sci B 
2014;15:281-8.

54. Yu PJ, Jin H, Zhang JY, et al. Pyranocoumarins isolated from Peucedanum praeruptorum Dunn suppress lipopolysaccharide-induced inflammatory response in murine macrophages through inhibition of NF- $\mathrm{kB}$ and STAT3 activation. Inflammation 2012;35:967-77.

Cite this article as: Xu R, Deng H, Gan L, Zhong L, Deng Y, Wang Q, Lv C, Huang L. Chinese herbal component, Praeruptorin E, enhances anti-asthma efficacy and prevents toxicity of aminophylline by targeting the NF- $\mathrm{\kappa B} / \mathrm{PXR} /$ CYP3A4 pathway. Ann Transl Med 2022;10(4):225. doi: 10.21037/atm-22-386
55. Zhou Y, Nie AQ, Chen S, et al. Downregulation of Renal MRPs Transporters in Acute Lymphoblastic Leukemia Mediated by the IL-6/STAT3/PXR Signaling Pathway. J Inflamm Res 2021;14:2239-52.

(English Language Editor: R. Scott) 